\title{
The Role of Temperature Inversions in the Generation of Seasonal and Interannual SST Variability in the Far Northern Bay of Bengal
}

\author{
MOTOKI NAGURA \\ Japan Agency for Marine-Earth Science and Technology, Kanagawa, Japan \\ TORU TERAO \\ Faculty of Education, Kagawa University, Kagawa, Japan \\ MASAHIRO HASHIZUME \\ Institute of Tropical Medicine (NEKKEN), Nagasaki University, Nagasaki, Japan
}

(Manuscript received 7 August 2014, in final form 29 January 2015)

\begin{abstract}
The northern Bay of Bengal is characterized by freshwater supply from the Ganges and Brahmaputra Rivers. The resulting shallow haline stratification and thick barrier layer lead to temperature inversions in fall and winter, that is, cool surface water overlaying warm subsurface water. This study examines sea surface temperature (SST) variability off Bangladesh and shows that temperature inversions play an essential role in generating seasonal and interannual SST variability there. Two satellite SST datasets reveal that the magnitude of SST variability has a local peak near the coast of Bangladesh on seasonal and interannual time scales. Output from a high-resolution ocean general circulation model, which is validated by satellite SST and Argo float observations, is used to calculate the mixed layer heat budget. Results show that inverted temperature profiles lead to SST warming on the seasonal time scale via heat exchange at the bottom of the mixed layer, which balances climatological atmospheric cooling in fall and winter. On interannual time scales, surface heat flux tends to damp SST variability, whereas heat exchange at the base of the mixed layer contributes to the growth of SST anomalies. SST off Bangladesh tends to be anomalously high in the year after an El Niño event and in the year of negative Indian Ocean dipole and La Niña events. The atmospheric circulations related to these climate modes force anomalous Ekman pumping, which advects more subsurface warm water to the surface in fall and winter, resulting in anomalous mixed layer warming. The deepening of the mixed layer entrains more subsurface warm water, which also contributes to anomalous warming.
\end{abstract}

\section{Introduction}

The northern Bay of Bengal is characterized by distinct surface stratification caused by freshwater supply from the Ganges and Brahmaputra Rivers. Surface water is freshened from summer to fall by river runoff associated with heavy precipitation during the summertime Indian monsoon, resulting in sharp haline stratification and a thin mixed layer along the coast (Howden and Murtugudde 2001; Rao and Sivakumar 2003; Akhil et al. 2014). Surface circulation further advects low-salinity water southward

Corresponding author address: Motoki Nagura, Japan Agency for Marine-Earth Science and Technology, Research Institute for Global Change, 2-15 Natsushima-cho, Yokosuka, Kanagawa 237-0061, Japan. E-mail: nagura@jamstec.go.jp along the western boundary of the bay in fall and winter (Han and McCreary 2001; Han et al. 2001; Akhil et al. 2014). In early spring, currents carry surface freshwater southward along the eastern boundary and also to the interior of the bay (Han and McCreary 2001; Vinayachandran et al. 2002; Thadathil et al. 2007). Meanwhile, zonal wind along the equatorial Indian Ocean is westerly in the transition seasons between the Indian and Australian monsoons, which deepens the equatorial thermocline. The deepened thermocline propagates eastward along the equator and then northward along the periphery of the bay (McCreary et al. 1993; Han and Webster 2002). The thin mixed layer and deep thermocline lead to a thick barrier layer (Sprintall and Tomczak 1992; Rao and Sivakumar 2003; Thadathil et al. 2007). An inverted vertical profile of temperature is another distinct feature 
of this region. The atmosphere cools the ocean in winter, and surface temperature decreases, but low-salinity water near the surface prevents vertical mixing from reaching deep levels. As a result, subsurface water remains warm, resulting in temperature inversions (Shetye et al. 1996; Girishkumar et al. 2013), which are widely observed in the bay from fall to winter (Thadathil et al. 2002).

Temperature inversions can have a significant impact on the heat budget of the surface mixed layer, because the mixed layer can be warmed by vertical heat advection, entrainment, or vertical diffusion at its base (Han et al. 2001; de Boyer Montégut et al. 2007; Wang et al. 2012; Girishkumar et al. 2013; Akhil et al. 2014). On the other hand, some studies based on numerical experiments (Howden and Murtugudde 2001; de Boyer Montégut et al. 2007) and observations (Shenoi et al. 2002, 2005) claimed that the mixed layer heat budget in the Bay of Bengal was mostly dominated by surface heat flux forcing. This result may partly be due to the averaging over the entire bay adopted by Howden and Murtugudde (2001), de Boyer Montégut et al. (2007), and Shenoi et al. (2002, 2005), which blurred the effects of temperature inversions tightly trapped near the coast. Shenoi et al. $(2002,2005)$ also examined the heat budget as the average over the upper $50 \mathrm{~m}$, which possibly eliminated features related to shallow surface stratification. Han et al. (2001) found that model SST was warmed by about $1^{\circ} \mathrm{C}$ if they included river runoff in their 4.5-layer model. The effect of haline stratification can be misrepresented in their model because of the low vertical resolution. Rao et al. (2002) suggested that the thick barrier layer prohibited thermocline movement from affecting SST variability along the coast of the bay, but they did not specify what process controlled SST variability. Wang et al. (2012) and Girishkumar et al. (2013) found nonnegligible influence of temperature inversions on SST. The former was based on numerical experiments with an ocean general circulation model (OGCM) and focused on short-term variability related to the passages of two cyclones; the latter used 11-month records from a moored buoy deployed at the interior of the bay. Neither could examine climatological seasonal cycle nor interannual variability.

The purpose of this study is to examine seasonal and interannual SST variability and the associated mixed layer heat budget off Bangladesh, where the amount of river runoff is largest and the barrier layer is thickest (Thadathil et al. 2007). The mean SST off Bangladesh is higher than $28^{\circ} \mathrm{C}$ except in winter (Rao et al. 1989), which is high enough to maintain active generation of organized convections (Gadgil et al. 1984). SST variability in this region can have a significant impact on atmospheric circulation. Furthermore, the northern Bay of Bengal is surrounded by densely populated areas, and environmental fluctuations can have important impacts on society. For example, earlier studies demonstrated that SST off Bangladesh was associated with cholera incidence in Dhaka, the capital and largest city in Bangladesh (Lobitz et al. 2000; Constatin de Magney et al. 2008; Hashizume et al. 2011).

The rest of this paper is organized as follows. Section 2 describes satellite SST datasets and an OGCM that we adopt. The OGCM is integrated with high horizontal and vertical grid intervals, which can be beneficial for the simulation of variability in coastal areas. We describe SST variability in the Bay of Bengal using the data and model output in section 3. Section 4 presents the mixed layer heat budget, and section 5 discusses the relationship with large-scale climate modes. The last section summarizes the main results.

\section{Data and model}

\section{a. Data}

We use two SST datasets. The first one is the monthly averaged National Oceanic and Atmospheric Administration (NOAA) optimally interpolated (OI) SST dataset (Reynolds and Smith 1994; Reynolds et al. 2002). This dataset is constructed from infrared SST data obtained from the Advanced Very High Resolution Radiometer (AVHRR) and in situ (moored buoy, ship, and drifter) observations. Data are optimally interpolated onto a $1^{\circ} \times 1^{\circ}$ grid for the period from November 1981 to the present. The AVHRR cannot retrieve SSTs in cloudcovered regions. The retrieval algorithms are statistically tuned by regression against in situ observations. The second SST dataset is the monthly averages of the Tropical Rainfall Measuring Mission (TRMM) Microwave Imager (TMI) SST (Gentemann et al. 2004), which is higher in spatial resolution $\left(0.25^{\circ} \times 0.25^{\circ}\right)$ than NOAA OI SST but shorter in the available period (from December 1997 to the present). TMI SST is based on measurements by a passive microwave radiometer, which has cloud-penetrating capabilities. It is retrieved using a physically based algorithm, that is, a radiative transfer model.

A monthly temperature and salinity dataset based on Argo float observations (Roemmich and Gilson 2009) is used to validate OGCM results. After an initial quality check, float observations are linearly interpolated in the vertical direction and horizontally mapped onto a $1^{\circ} \times 1^{\circ}$ grid using a least squares fit and an objective analysis based on statistics derived from sample correlation estimates. The period for the gridded Argo dataset is from January 2004 to October 2013.

Monthly averages of the National Centers for Environmental Prediction-National Center for Atmospheric Research (NCEP-NCAR) reanalysis data (Kalnay et al. 
1996) are used to examine atmospheric variability. The NCEP-NCAR reanalysis data are on a $2.5^{\circ} \times 2.5^{\circ}$ grid and available from January 1948 to the present. We also use monthly precipitation from the Global Precipitation Climatology Project (GPCP) dataset (Huffman et al. 1997), which is on a $2.5^{\circ} \times 2.5^{\circ}$ grid and available from January 1979 to June 2011. The GPCP dataset is a combination of gauge observations with satellite estimates.

\section{b. Model}

The OGCM we use is the OGCM for the Earth Simulator (OFES) developed at the Japan Agency for MarineEarth Science and Technology (JAMSTEC; Masumoto et al. 2004; Sasaki et al. 2006, 2008). The OFES is based on the Modular Ocean Model version 3 (MOM3), developed at the NOAA/Geophysical Fluid Dynamics Laboratory (Pacanowski and Griffies 1999). The model domain is from $75^{\circ} \mathrm{S}$ to $75^{\circ} \mathrm{N}$, with a horizontal grid spacing of $0.1^{\circ}$ and 54 vertical levels. The vertical resolution is $5 \mathrm{~m}$ near the surface, and the upper $50 \mathrm{~m}$ of the model includes eight levels. The partial cell method (Pacanowski and Gnanadesikan 1998) is adopted to represent the topography realistically. The $K$-profile parameterization scheme (KPP scheme; Large et al. 1994) and a biharmonic operator are used for the calculation of vertical and horizontal diffusivity, respectively.

OFES is spun up using daily averages of the NCEP reanalysis data for the period from 1950 onward. Momentum flux and shortwave radiation obtained from the reanalysis are directly used to drive the model. Latent and sensible heat fluxes and longwave radiation are calculated from model SST and the reanalysis data using a standard bulk formula proposed by Rosati and Miyakoda (1988). Surface wind speed, relative humidity, and air temperature at sigma level 0.995 from the reanalysis are used in the heat flux calculation. The freshwater and salt flux are calculated as $P-E$ and $(E-P) \times \mathrm{SSS}$, respectively, where $P$ is precipitation obtained from the reanalysis, $E$ is evaporation calculated from a bulk formula, and SSS is model sea surface salinity. The total seawater volume in the model is kept the same during the integration. According to Janowiak et al. (1998), reanalysis precipitation agrees well with the GPCP data in the northern Bay of Bengal.

In addition, the model sea surface salinity is restored to the monthly surface salinity climatology of the World Ocean Atlas 1998 (Boyer et al. 1998a,b,c) with the restoring time scale of 6 days. This restoration aims to represent climatological freshwater supply from river runoff. In the next subsection, we show that the model is able to reproduce a realistic barrier layer and a temperature inversion in the Bay of Bengal. In this study, we analyze fields output at 3-day intervals. The analysis period is from 1982 to 2012 for the consistency with NOAA OI SST.

\section{c. Model validation}

OFES is able to simulate surface zonal jets (Masumoto et al. 2004; Nagura and McPhaden 2014) and intraseasonal wave activity (Nagura et al. 2014) in the equatorial Indian Ocean (figure not shown). Here we compare surface stratification in the model with observations. We define the isothermal layer depth as the depth where temperature is lower than SST by $\delta T=1.0^{\circ} \mathrm{C}$, where $T$ denotes potential temperature. We follow Shetye et al. (1996), Rao and Sivakumar (2003), and Thadathil et al. (2007) in using $1.0^{\circ} \mathrm{C}$ as $\delta T$. The mixed layer depth is defined as the depth where potential density, $\rho_{\theta}=\rho_{\theta}(T, S)$, is larger than the surface by $\delta \rho_{\theta}=\left(\partial \rho_{\theta} / \partial T\right) \delta T$, where $S$ denotes salinity. The term $\partial \rho_{\theta} / \partial T$ is calculated for SST and sea surface salinity. The barrier layer thickness is defined as the difference between the isothermal layer depth and mixed layer depth.

The barrier layer in OFES is thin in April-May and thickened in June-October in the northern periphery of the Bay of Bengal (Fig. 1), as is shown by Thadathil et al. (2007), who based their analysis on in situ observations. The thick barrier layer in the northern bay is transported southwestward by coastal currents in fall and winter (Han and McCreary 2001; Thadathil et al. 2007). The thick barrier layer in OFES also expands southwestward from the northern apex of the bay, although the timing of the expansion is earlier compared to the results from past studies. The model barrier layer is thickened in the interior of the bay in January-March, which compares well with observations (Thadathil et al. 2007). These results indicate that OFES reproduces the overall pattern of the observed barrier layer thickness, although river runoff is included in a crude manner (i.e., surface salinity restoration).

Argo observations show a thin barrier layer in May and a thick barrier layer in November in the northern bay (Fig. 2). Observed temperature monotonically decreases to the 100-m depth in May, whereas a temperature inversion is observed in November in the upper $30 \mathrm{~m}$. Observed salinity is lower near the surface than at subsurface in both May and November. Model results compare well with observations, in particular the thick barrier layer and the temperature inversion in November, although the simulated mixed layer is too thick then. The discrepancy may be attributable to the coarseness of vertical grids of the model or an imperfectness of the KPP mixing scheme. Zaron and Moum (2009) pointed out that the KPP scheme tended to overpredict the surface mixed layer thickness and thermal diffusivity below the surface compared to microstructure turbulence observations. In 

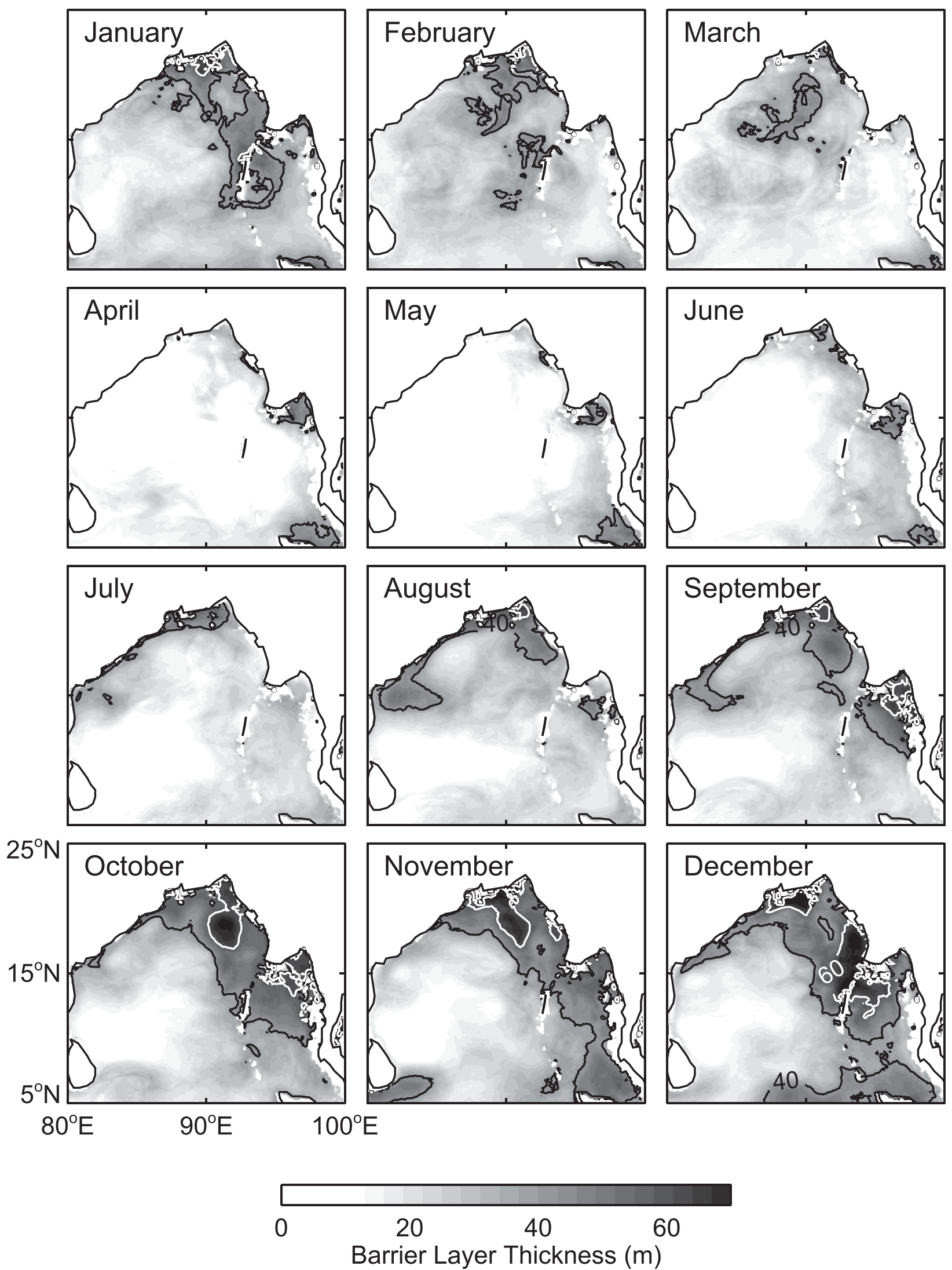

FIG. 1. Monthly climatological barrier layer thickness in OFES. Black and white contours show 40 and $60 \mathrm{~m}$, respectively. Climatologies are defined for the period from August 2002 to September 2006 in consistency with Thadathil et al. (2007). 
Argo

(a)

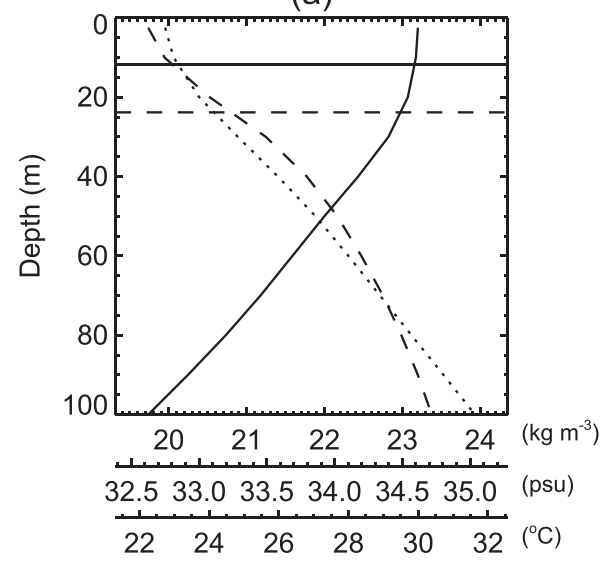

(b)

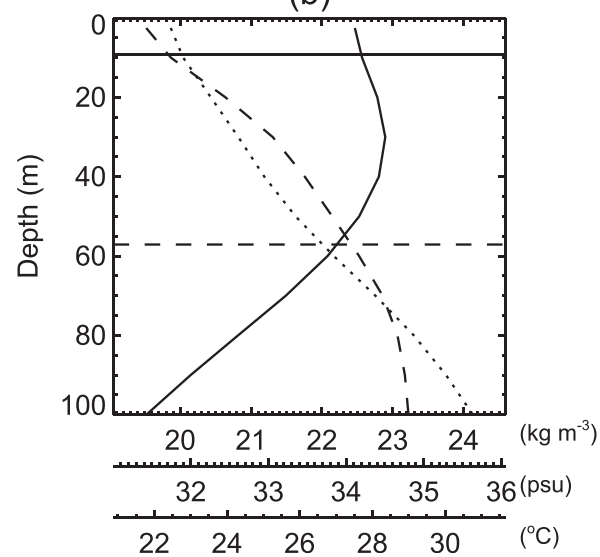

OFES

(c)

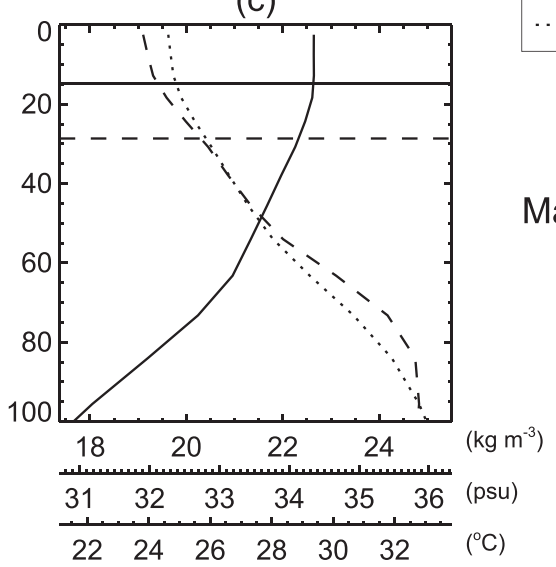

(d)

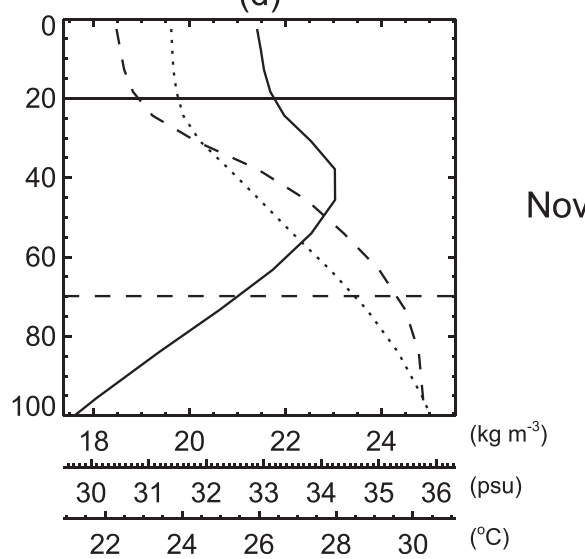

FIG. 2. The vertical profiles of climatological temperature (solid line), salinity (dashed line), and potential density (dotted line) at $20^{\circ} \mathrm{N}, 90^{\circ} \mathrm{E}$ for (a),(b) Argo float observations and (c),(d) OFES results in (top) May and (bottom) November. Solid and dashed horizontal lines illustrate the mixed layer depth and isothermal layer depth, respectively, defined by $\delta T=1.0^{\circ} \mathrm{C}$. Climatologies are calculated for the period of Argo float observations (January 2004-December 2012).

spite of the discrepancy in the mixed layer thickness, the model barrier layer thickness is very close to that of observations $(\sim 70 \mathrm{~m})$.

SST simulated by OFES sometimes shows an unrealistic trend, which is possibly attributable to the forcing fields from the NCEP reanalysis. We here focus on variability averaged over a box off Bangladesh $\left(20^{\circ}-23^{\circ} \mathrm{N}\right.$, $88^{\circ}-92^{\circ} \mathrm{E}$; defined in Fig. 3), which is the analysis region of this study. SST anomalies are calculated by subtracting monthly climatology, and a 3-month triangle filter is applied twice. These anomalies include interannual or longer-period variability and possibly a trend. Owing to the existence of periodical variability, the time series has a serial correlation, which may cause a spurious estimate of trends (Fomby and Vogelsang 2002). To avoid this error, we use the trend-detection method proposed by Fomby and Vogelsang (2002). Then, anomalies are detrended using the detected trend, and the standard deviation of detrended anomalies is used as a metric for the amplitude of interannual variability. The results show that the warming trend of the box-averaged model SST is $0.27^{\circ} \mathrm{C}(10 \mathrm{yr})^{-1}$, which is significant at the $90 \%$ confidence level and comparable in magnitude to interannual variability (Table 1). NOAA OI SST does not show any significant trend. In the forcing fields of the model, we found that NCEP wind speed and shortwave radiation averaged over the same box had decreasing and increasing trends, respectively, both of which lead to an increase of surface heat flux and possibly cause the warming trend of model SST. In the following sections, we detrend model SST before the analysis. We do not detrend the NCEP reanalysis data, because the trends in the NCEP data are small in magnitude compared to interannual variability. The results shown below hardly 
NOAA OI

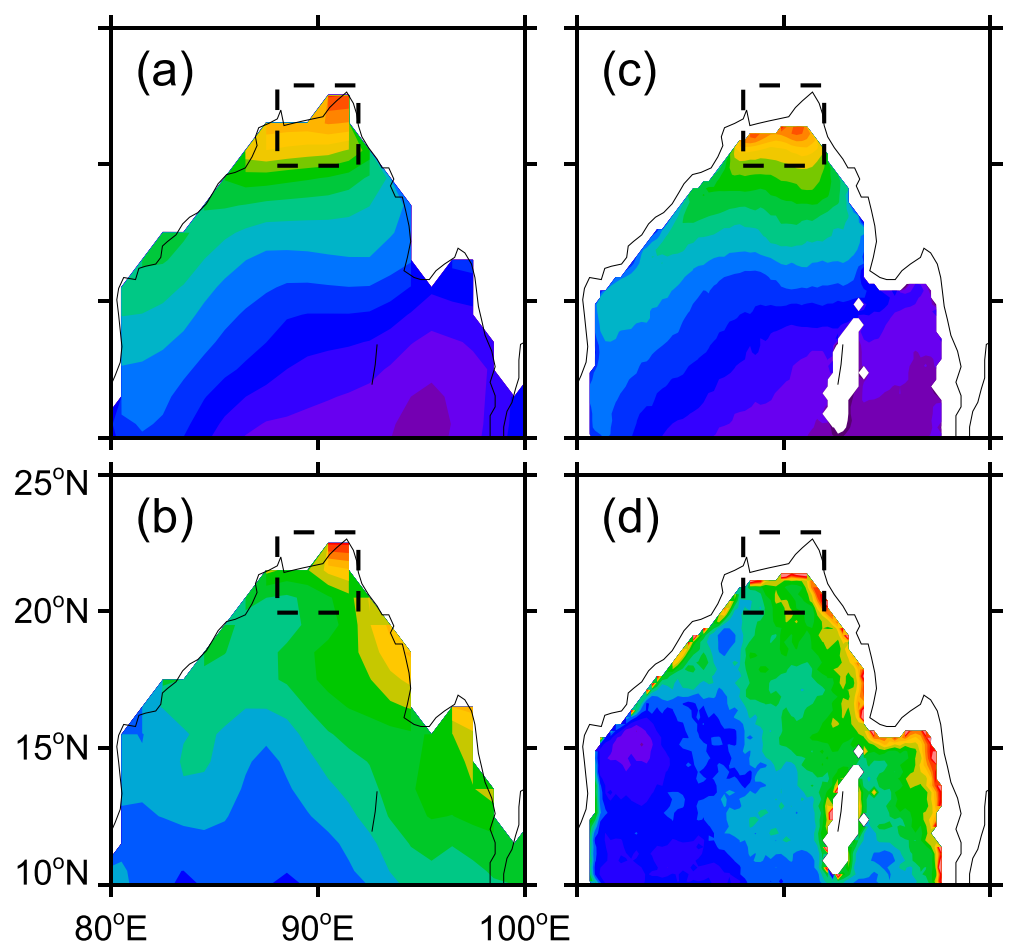

TMI
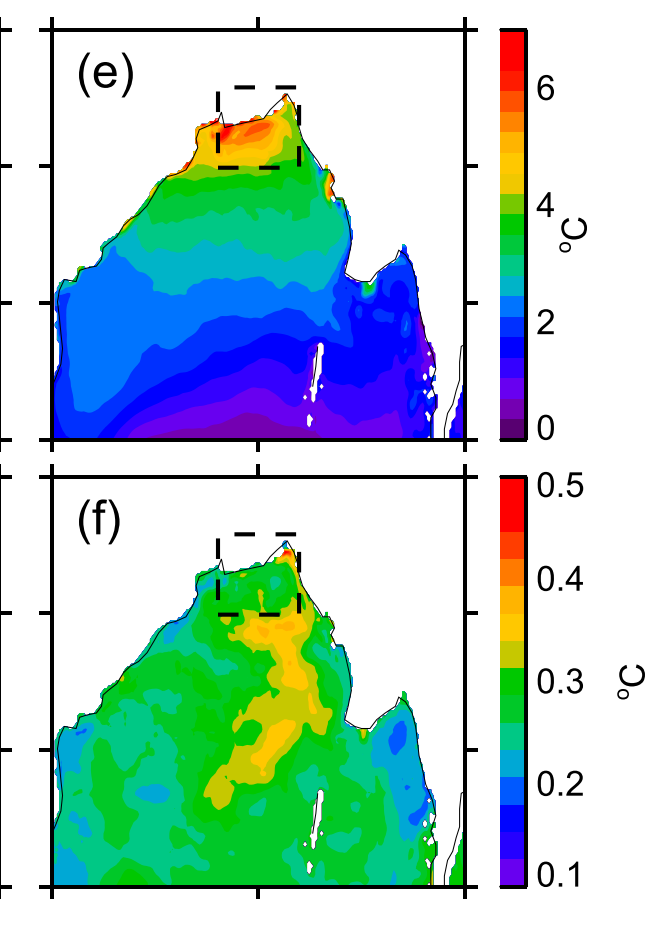

OFES

FIG. 3. (a),(c),(e) The difference of climatological SST between January and July (July minus January) and (b),(d),(f) the standard deviations of interannual SST anomalies. The left, middle, and right panels are for NOAA OI SST, TMI SST, and OFES, respectively. A 3 -month triangle filter was applied twice to smooth anomalies. Black dashed line illustrates the off-Bangladesh box $\left(20^{\circ}-23^{\circ} \mathrm{N}, 88^{\circ}-92^{\circ} \mathrm{E}\right)$. The period of climatology is from 1982 to 2012 for NOAA OI SST and OFES and from 2004 to 2012 for TMI SST.

change if we detrend NCEP forcing time series before the analysis.

\section{SST variability}

The amplitude of seasonal variability in observed SST is largest in the northern bay and decreases toward the south (Figs. 3a,c). The maximum amplitude is about $6^{\circ} \mathrm{C}$. Seasonal SST variability is larger in the western part of the bay than in the east. OGCM results compare well with observations in magnitude and spatial pattern
(Fig. 3e). Positive spatial correlations of 0.92 between NOAA OI SST and OFES SST and 0.95 between TMI SST and OFES SST support the visually apparent largescale agreement. On interannual time scales, the amplitude of observed SST variability is large along the northern and eastern boundaries (Figs. 3b,d). The magnitude of simulated SST anomalies shows a local maximum in the far northern Bay of Bengal as is observed, but lacks local peaks along the eastern boundary and is overestimated in the southwestern part of the bay (Fig. 3f). Also, model SST anomalies show a dubious

TABLE 1. Linear trends and the ratio of 10-yr increment of the trend to the amplitude of interannual variability for anomalies averaged over the off-Bangladesh box $\left(20^{\circ}-23^{\circ} \mathrm{N}, 88^{\circ}-92^{\circ} \mathrm{E}\right)$. Results shown in boldface are significant at the $90 \%$ confidence level. Anomalies are defined as the deviation from monthly climatology and smoothed by applying a 3-month triangle filter twice. The trends and their significance are estimated using statistics labeled $\tilde{\beta}_{2}$ and $t-\mathrm{PS}_{T}$ (Fomby and Vogelsang 2002). The standard deviation of detrended anomalies is used as a metric for the amplitude of interannual variability.

\begin{tabular}{|c|c|c|}
\hline Variable & Trend & $\begin{array}{c}\text { Ratio to interannual } \\
\text { variability }\end{array}$ \\
\hline OFES SST & $0.27^{\circ} \mathrm{C}(10 \mathrm{yr})^{-1}$ & 0.88 \\
\hline NOAA OI SST & $-0.06^{\circ} \mathrm{C}(10 \mathrm{yr})^{-1}$ & 0.18 \\
\hline NCEP surface wind speed & $-0.22 \mathrm{~m} \mathrm{~s}^{-1}(10 \mathrm{yr})^{-1}$ & 0.50 \\
\hline NCEP downward shortwave radiation & $2.28 \mathrm{~W} \mathrm{~m}^{-2}(10 \mathrm{yr})^{-1}$ & 0.33 \\
\hline
\end{tabular}


NOAA OI SST

(a)

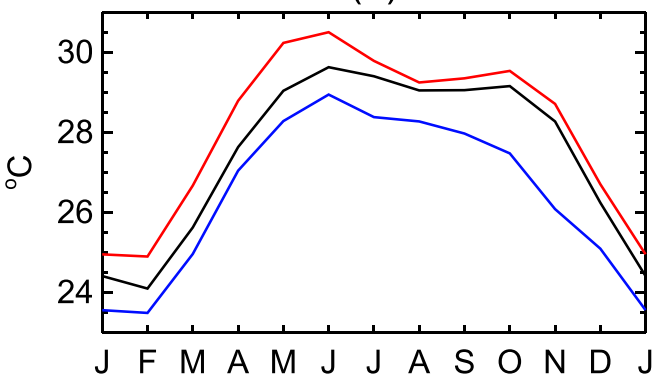

TMI SST (b)

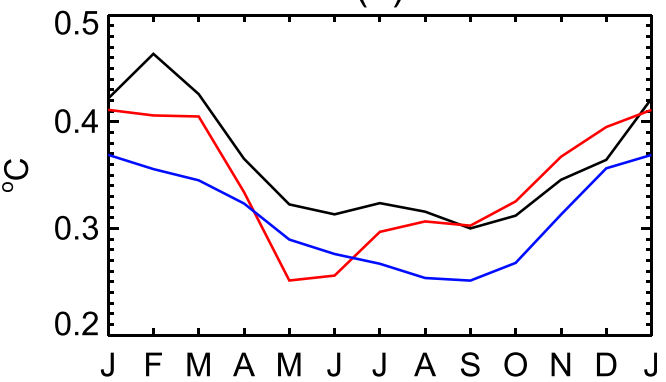

(c)

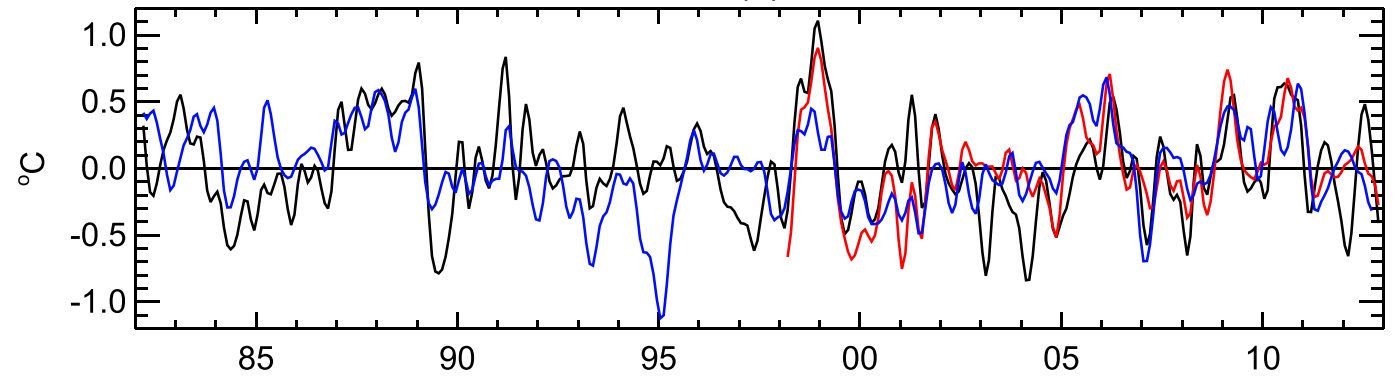

FIG. 4. (a) Monthly SST climatologies, (b) the standard deviations of interannual SST anomalies, and (c) the time series of interannual SST anomalies averaged over the off-Bangladesh box $\left(20^{\circ}-23^{\circ} \mathrm{N}, 88^{\circ}-92^{\circ} \mathrm{E}\right)$. Black, red, and blue lines are for NOAA OI SST, TMI SST, and OFES. A 3-month triangle filter was applied twice to smooth interannual anomalies. The period of climatology is from 1982 to 2012 for NOAA OI SST and OFES and from 2004 to 2012 for TMI SST. The increasing trend in OFES SST anomalies has been removed.

local maximum of amplitude in the interior of the bay along about $90^{\circ} \mathrm{E}$. We conducted a brief analysis of the mixed layer heat budget, the results of which showed the contribution of horizontal heat advection to the generation of SST anomalies along $90^{\circ} \mathrm{E}$. This suggests that the model forcing generates unrealistic horizontal advection in this region. Here we focus on variability in the region off Bangladesh (defined by black dashed boxes in Fig. 3), where the agreement between observations and the model is relatively good, and seasonal and interannual SST variability shows a local maximum of amplitude.

Climatologies of the observed SST averaged over the box are highest in June and lowest in February (Fig. 4a). The climatological SST from OFES agrees well with observations in terms of seasonal cycle, but model SST is systematically lower than observations by a few degrees. SST from OFES is defined at $2.5-\mathrm{m}$ depth, whereas satellite measurements are representative of skin temperature at depths of approximately $O(10) \mu \mathrm{m}$ (Castro et al. 2010), which can be a possible cause of the discrepancy. Also, there can be an error in the reanalysis surface atmospheric data used to force the model (e.g., Wang and McPhaden 2001). The satellite SST datasets possibly include errors owing to the paucity of in situ observations used for calibration (Emery et al. 2001).

The standard deviation of the box-averaged interannual SST anomalies peaks in February for NOAA OI SST and in January for TMI SST (Fig. 4b; see appendix A for the calculation method). This indicates that SST displays the most interannual variability in winter. The standard deviation of the model SST anomalies is smaller than that of the observed SST anomalies except in May and June in comparison with TMI SST. Nevertheless, simulated SST agrees well with observations in terms of the seasonality of interannual variations. The time series of the box-averaged SST anomalies is highly correlated between the two satellite observations and the model, which tend to be positive in 1987/88, 1998/99, 2005/06, and 2010 and negative in 1984/85, 1989, and 1999/2000. The correlation coefficient between boxaveraged NOAA OI SST and TMI SST anomalies exceeds the $99 \%$ confidence limit $(r=0.66)$, indicating that the two different datasets show consistent variability. Here, degrees of freedom for the correlation coefficient are calculated based on the integral time scale (Davis 1976). The correlation coefficients between 


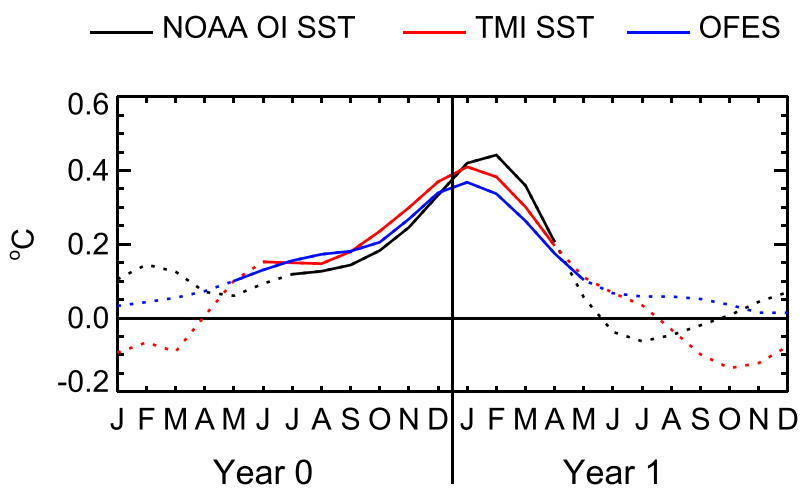

FIG. 5. SST anomalies averaged over the off-Bangladesh box $\left(20^{\circ}-23^{\circ} \mathrm{N}, 88^{\circ}-92^{\circ} \mathrm{E}\right)$ and regressed onto its normalized DJF mean for NOAA OI SST (black), TMI SST (red), and OFES (blue). A 3-month triangle filter was applied twice. Solid lines show the regression coefficients that exceed the $95 \%$ confidence limit. The period of climatology is from 1982 to 2012 for NOAA OI SST and OFES and from 2004 to 2012 for TMI SST.

observed and simulated SST anomalies exceed the $99 \%$ confidence limit as well ( $r=0.41$ between NOAA OI SST and OFES; $r=0.74$ between TMI SST and OFES), showing that the model simulation is successful, although model results sometimes show an apparent discrepancy from observations (e.g., in 1994/95).

We calculate a typical SST evolution using a seasonally stratified regression analysis (see appendix A). The boxaveraged SST anomalies in each month are regressed onto its December-February (DJF) mean, after normalizing the DJF mean by its standard deviation. We refer to the period leading the DJF as year 0 and that following as year 1. Results show that an SST anomaly off Bangladesh typically grows in summer and fall of year 0 , peaks in late winter of year 1, and decays afterward (Fig. 5). As this analysis is based on linear regression, the same seasonal evolution occurs with anomalies of the opposite sign when the box-averaged SST anomalies reach a negative peak at the end of year 0 . The typical magnitude of the regressed SST anomalies is about $0.4^{\circ} \mathrm{C}$. The regressed OGCM SST anomalies compare well with observations in terms of seasonal evolution and amplitude. These results show that OFES can reproduce the time scale, or the "memory," of interannual SST variability off Bangladesh.

\section{Mixed layer heat budget}

In this section, we examine the mixed layer heat budget in the off-Bangladesh box using OFES output. We first describe the method and then present results.

\section{a. Method}

The mixed layer heat budget is expressed as (see appendix B for details)

$$
\begin{aligned}
\frac{\partial \bar{T}}{\partial t}= & \frac{Q}{\rho_{0} c_{p} h}-\overline{\mathbf{u}_{H}} \cdot \nabla_{H} \bar{T} \\
& -\frac{\Delta T}{h}\left(\frac{\partial h}{\partial t}+\mathbf{u}_{\mathrm{Hb}} \cdot \nabla_{H} h+w_{b}\right)+(\text { Diff }),
\end{aligned}
$$

where $t$ denotes time and the overbar denotes the average from the sea surface to the bottom of the mixed layer. The subscript $b$ denotes the value at the bottom of the mixed layer. The variable $h$ is mixed layer depth, which is defined in section $2 \mathrm{c}$, and $\rho_{0}$ and $c_{p}$ are the mean density and specific heat of seawater $\left(1035 \mathrm{~kg} \mathrm{~m}^{-3}\right.$ and $3939 \mathrm{~J} \mathrm{~K}^{-1} \mathrm{~kg}^{-1}$, respectively). The variable $Q$ is "effective" heat flux, which is calculated as $Q=Q_{\text {surf }}-Q_{\text {pen }}$, where $Q_{\text {surf }}$ is heat flux at the sea surface and $Q_{\text {pen }}$ is the heat loss by shortwave radiation that penetrates through the mixed layer bottom. The vector $\mathbf{u}_{H}=(u, v)$ is a horizontal velocity vector, where $u$ and $v$ are zonal and meridional velocity, respectively. The term $\nabla_{H}=\left(\partial_{x}, \partial_{y}\right)$ is the horizontal gradient operator, where $x$ and $y$ denote the zonal and meridional coordinates, respectively. The term $\Delta T=\bar{T}-T_{b}$ is the difference between temperature averaged over the mixed layer and that at the bottom of the mixed layer. The variable $w$ is vertical velocity. We refer to the first, second, and third terms on the right-hand side (rhs) of Eq. (1) as the surface heat flux term, the horizontal advection term, and the vertical process term, respectively. The vertical process term consists of the three terms. The first term, $-(\Delta T / h) \partial_{t} h$, represents the effect of entrainment/detrainment into/out of the surface mixed layer. The second, $-(\Delta T / h) \mathbf{u}_{\mathrm{Hb}} \cdot \nabla_{H} h$, represents horizontal advection across the bottom of the mixed layer, which is effective when the bottom of the mixed layer varies spatially. The third, $-(\Delta T / h) w_{b}$, represents vertical advection across the bottom of the mixed layer.

The last term in Eq. (1), (Diff), denotes the diffusion term. We estimate this term in two ways. First, we estimate it indirectly as the residual of the budget. Model output is provided as snapshots taken at every 3 days, which causes sampling errors. The calculation of the diffusion term as the residual may be affected by those errors. Note that we confirmed that errors other than the sampling error are negligible (see appendix B). Second, we calculate the diffusion term explicitly as (see appendix B for the derivation)

$$
\text { (Diff) }=\frac{1}{h}\left[-\left.K_{T} \frac{\partial T}{\partial z}\right|_{b}+\int_{-h}^{0} D_{h}(T) d z\right]
$$

where $z$ is the vertical coordinate, $K_{T}$ denotes the vertical diffusion coefficient, and $D_{h}(T)$ denotes the horizontal diffusion term at each level. The variable $K_{T}$ is 


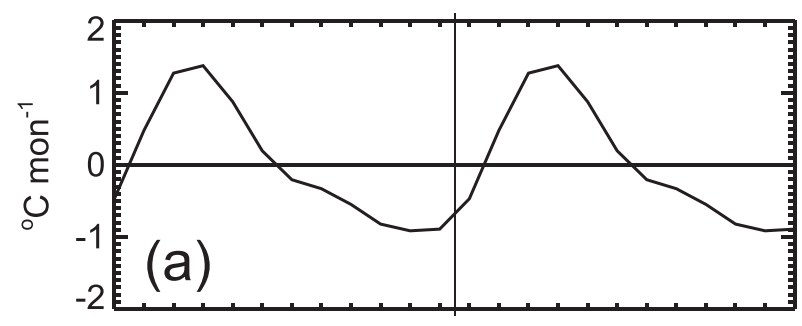

J FMAM J J ASOND J FMAM J J ASOND
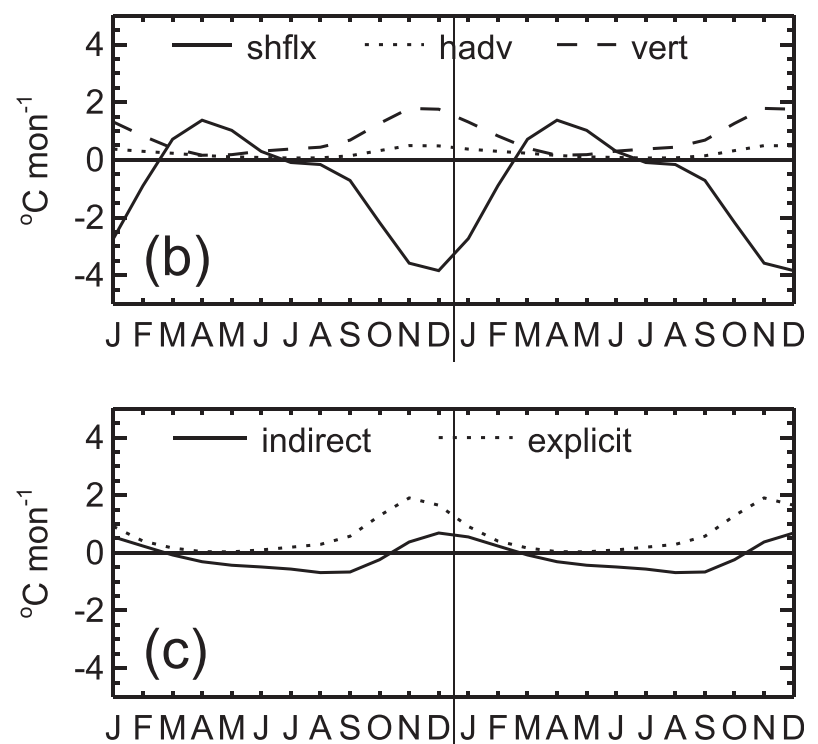

FIG. 6. The climatological mixed layer heat budget averaged over the off-Bangladesh box $\left(20^{\circ}-23^{\circ} \mathrm{N}, 88^{\circ}-92^{\circ} \mathrm{E}\right)$. (a) The temperature tendency term; (b) the surface heat flux term (solid line), the horizontal advection term (dotted line), and the vertical process term (dashed line); and (c) the diffusion term indirectly estimated as the residual of the budget (solid line) and that calculated explicitly (dotted line). A 3-month triangle filter is applied twice to the time series of the heat budget terms.

calculated using the KPP scheme, $\partial T / \partial z$ is calculated using temperature output, and $D_{h}(T)$ is calculated using a biharmonic formula and temperature output. The diffusion term is calculated using temperature at several adjacent time steps in the model integration, whereas we calculate Eq. (2) using temperature output at a single time step for simplicity, which may cause errors. We compare results of the two estimates in the next section.

\section{b. Results}

The climatological mixed layer temperature averaged over the off-Bangladesh box rises in February-June and decreases in the rest of year (Fig. 6a). This seasonal variability is mainly due to surface heat flux (Fig. 6b). The mixed layer is thin $(h<20 \mathrm{~m})$ because of surface freshening (Fig. 7a) and therefore is sensitive to surface heat flux. The thin mixed layer allows excess solar (a)

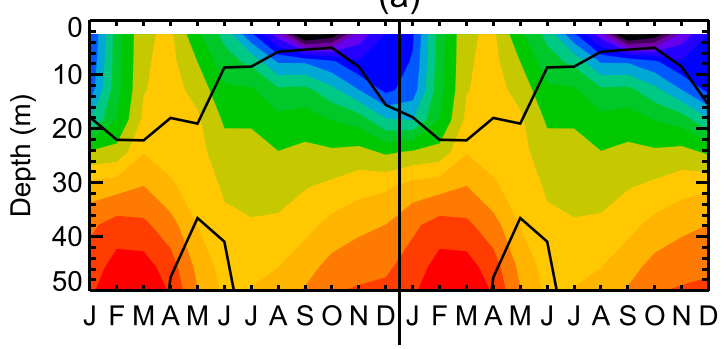

psu

36

32

28

24

(b)

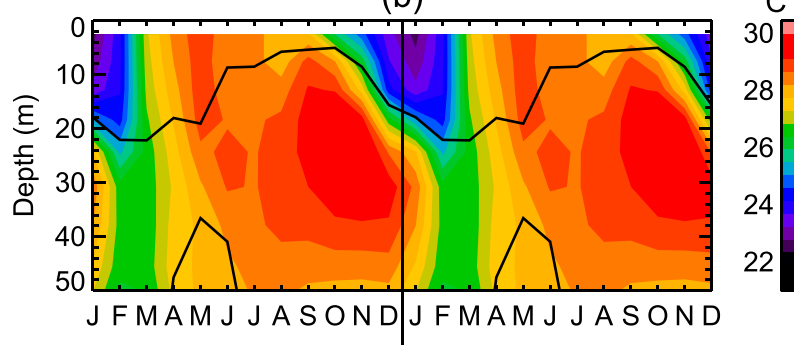

FIG. 7. The vertical structures of climatological (a) salinity and (b) temperature in OFES at the center of the off-Bangladesh box $\left(21.5^{\circ} \mathrm{N}, 90^{\circ} \mathrm{E}\right)$. The upper and lower solid lines in each panel illustrate the bottom depths of the climatological mixed and isothermal layer, respectively, defined by $\delta T=1.0^{\circ} \mathrm{C}$.

radiation to penetrate across the bottom (Sengupta et al. 2002). The heat loss due to this effect is about 30$50 \mathrm{~W} \mathrm{~m}^{-2}$ in the off-Bangladesh box. The surface heat flux term shows a cooling tendency in July-February, which is counteracted by warming of the horizontal advection and vertical process terms. Climatological temperature shows a clear inversion from August to February near the bottom of the mixed layer (Fig. 7b). The mixed layer is deepened from October to February, when subsurface warm water is entrained to the surface, resulting in warming of the vertical process term (Fig. 6b). In addition, climatological upwelling in the off-Bangladesh box brings warm subsurface water to the surface. Horizontally, wintertime SST shows a minimum along the coast of Bangladesh, and horizontal advection leads to warm water outside of the box flowing into the box, which also results in warming. The indirectly estimated diffusion term is systematically lower than the explicitly calculated diffusion term, but both show a warming tendency from November to February (Fig. 6c), indicating that warm subsurface water is diffused to the surface. This result is consistent with de Boyer Montégut et al. (2007), who conducted an online calculation of the mixed layer heat budget and showed warming due to vertical diffusion in the northern Bay of Bengal.

The SST anomaly off Bangladesh tends to grow in year 0 , reaches a peak in January of year 1, and decays in year 1 (Fig. 5). To obtain the corresponding mixed layer heat budget, we regress anomalies of the budget terms 

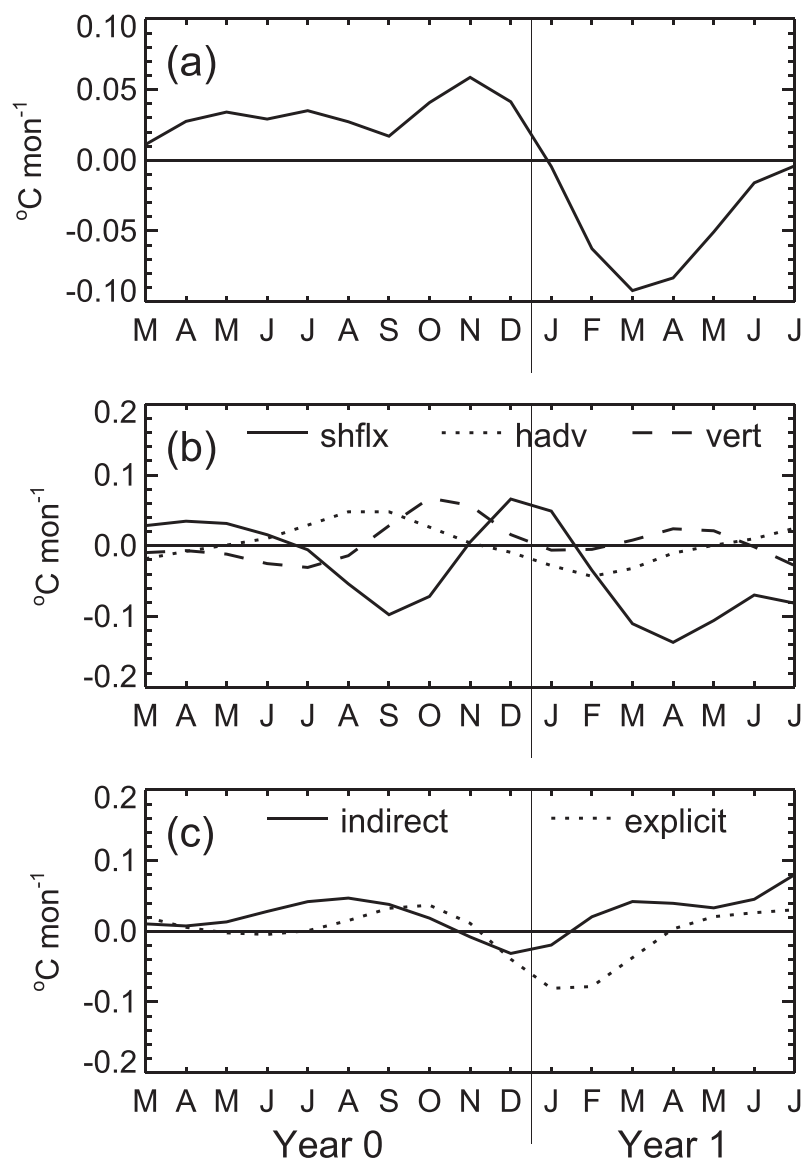

FIG. 8. As in Fig. 6, but for interannual anomalies regressed onto the normalized DJF mean of OFES SST anomalies averaged over the off-Bangladesh box $\left(20^{\circ}-23^{\circ} \mathrm{N}, 88^{\circ}-92^{\circ} \mathrm{E}\right)$. A 3-month triangle filter was applied twice.

onto the normalized off-Bangladesh DJF SST anomalies (Fig. 8). The results show that the growth of the SST anomaly in summer and fall of year 0 results from the horizontal advection and vertical process terms (Figs. 8a,b). The surface heat flux term is negative in July-October of year 0 and tends to suppress the SST growth. Both the two estimates of the diffusion term show warming anomalies in late summer and fall of year 0, contributing to the SST growth as well (Fig. 8c). When off-Bangladesh SST anomalies are of the opposite sign, anomalies of the budget terms are of the opposite sign too, contributing to the growth of negative SST anomalies in a similar manner.

To examine detailed processes, we decompose the heat budget terms. An anomaly of the surface heat flux term shown by the solid line in Fig. $8 \mathrm{~b}$ is decomposed into two:

$$
\left(\frac{Q}{\rho_{0} c_{p} h}\right)^{\prime}=\frac{Q^{\prime}}{\rho_{0} c_{p}[h]}-\frac{[Q]}{\rho_{0} c_{p}[h]} \frac{h^{\prime}}{[h]},
$$

where prime denotes interannual anomaly and square brackets denote monthly climatology. The first and second terms on the rhs are shown in Fig. 9a. We have neglected the terms related to the product of anomalies, because those terms are small in magnitude. The first term is the contribution from a surface heat flux anomaly. The effective surface heat flux anomalies $\left(Q^{\prime}\right)$ regressed onto the box-averaged SST anomalies are negative after June of year 0 (Fig. 9b), and the first term of Eq. (3) is in phase with $Q^{\prime}$ (Fig. 9a, solid line). This indicates that the atmospheric forcing acts to prevent the growth of a positive SST anomaly. The effective heat flux $(Q)$ consists of the surface heat flux $\left(Q_{\text {surf }}\right)$ and shortwave penetration $\left(Q_{\text {pen }}\right)$. The surface heat flux $Q_{\text {surf }}$ further consists of shortwave radiation, longwave radiation, and latent and sensible heat fluxes. Usually, shortwave radiation and latent heat flux are the main contributors. Shortwave radiation anomalies regressed onto DJF box-averaged SST are positive in July-August of year 0 and indistinguishable from zero afterward (Fig. 9c, red), which do not account for negative surface heat flux anomalies. It is latent heat flux anomalies that are negative at the end of year 0 (Fig. 9c, blue). The amplitude of SST and surface air temperature anomalies is $0.4^{\circ}$ (Fig. 5) and $0.2^{\circ} \mathrm{C}$ (Fig. 9d, black), respectively, at the end of year 0 . These temperature variations result in about $4 \mathrm{~W} \mathrm{~m}^{-2}$ decrease of latent heat flux. During the years of positive SST anomalies off Bangladesh, the mixed layer is thicker than normal after November of year 0 (Fig. 9d, red), which results in about $1.5 \mathrm{~W} \mathrm{~m}^{-2}$ reduction of solar penetration (Fig. 9e, black). These heat flux anomalies $\left(4 \mathrm{~W} \mathrm{~m}^{-2}\right.$ cooling and $1.5 \mathrm{~W} \mathrm{~m}^{-2}$ warming) end up with $2.5 \mathrm{~W} \mathrm{~m}^{-2}$ cooling, which roughly accounts for the effective surface heat flux anomalies at the end of year 0 .

The second term of Eq. (3) is the contribution from a mixed layer depth anomaly. This term shows warming anomalies from September of year 0 to February of year 1 (Fig. 9a, dotted). The thicker than normal mixed layer (Fig. 9d) and climatological surface cooling in fall and winter (Fig. 6b) indicate $h^{\prime} /[h]>0$ and $[Q] /\left(\rho_{0} c_{p}[h]\right)<0$, respectively, resulting in positive anomalies of the second term of Eq. (3). In other words, the anomalously thick mixed layer increases the heat capacity of the surface mixed layer and mitigates climatological cooling, which means anomalous warming. As wind speed anomalies are indistinguishable from zero (Fig. 9e, red), the anomalously thick mixed layer should be attributed to factors other than mechanical mixing.

An anomaly of the horizontal advection term (dotted line in Fig. 8b) is decomposed into the contribution from a velocity anomaly and that from a temperature anomaly: 

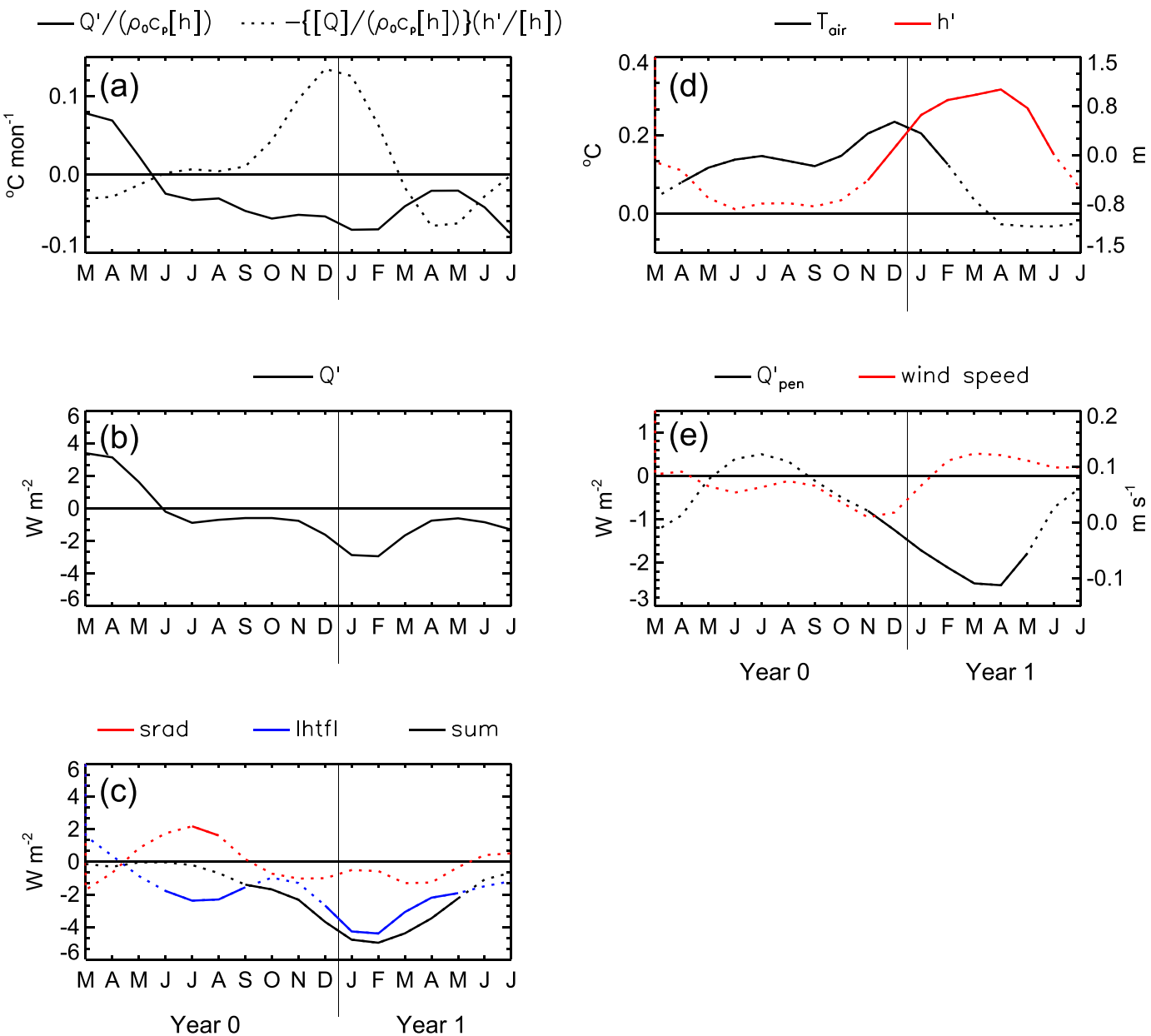

FIG. 9. Anomalies averaged over the off-Bangladesh box $\left(20^{\circ}-23^{\circ} \mathrm{N}, 88^{\circ}-92^{\circ} \mathrm{E}\right)$ regressed onto the normalized DJF mean of OFES SST anomalies averaged over the same box. (a) Contributions to the surface heat flux term from surface heat flux anomalies, $Q^{\prime} /\left(\rho_{0} c_{p}[h]\right)$ (solid line) and from mixed layer depth anomalies, $-\left\{[Q] /\left(\rho_{0} c_{p}[h]\right)\right\}\left(h^{\prime} /[h]\right)$ (dotted line). (b) OFES effective surface heat flux anomalies $\left(Q^{\prime}=Q_{\text {surf }}^{\prime}-Q_{\text {pen }}^{\prime}\right)$. (c) NCEP downward shortwave radiation anomalies (red), latent heat flux anomalies calculated from OFES SST and NCEP data (blue), and their sum (black). (d) NCEP surface air temperature anomalies (black) and OFES mixed layer depth anomalies (red). (e) Penetrated shortwave radiation anomalies $\left(Q_{\mathrm{pen}}^{\prime}\right.$, black) and NCEP wind speed anomalies (red). The scales for mixed layer depth in (d) and wind speed in (e) are shown on the right. A 3-month triangle filter was applied twice. The regression coefficients that exceed the $90 \%$ confidence level are shown by solid lines in (c)-(e).

$$
\left(-\overline{\mathbf{u}_{H}} \cdot \nabla_{H} \bar{T}\right)^{\prime}=-{\overline{\mathbf{u}_{H}}}^{\prime} \cdot\left[\nabla_{H} \bar{T}\right]-\left[\overline{\mathbf{u}_{H}}\right] \cdot \nabla_{H} \bar{T}^{\prime},
$$

the results of which are shown in Fig. 10a. Both terms show warming anomalies in June-October of year 0 , though their magnitude is small. Surface wind stress anomalies regressed onto the off-Bangladesh SST anomalies show that wind anomalies tend to be northeasterly in the Bay of Bengal in summer of year 0, which is stronger in the eastern side of the bay than in the west (Fig. 11a). The resulting Ekman downwelling anomaly leads to a clockwise circulation, which transports climatologically warmer water into the box and cooler water out of the box (Fig. 11b). A climatological counterclockwise circulation in summer and fall further advects the mixed layer temperature anomaly and causes warming (figure not shown). The second term of Eq. (4) shows a cooling anomaly from December of year 0 to May of year 1. These cooling anomalies are related to the wintertime climatological clockwise circulation, which transports anomalously cooler water into the box and warmer water out of the box (Fig. 11c).

The vertical process term is the sum of three terms, that is, the entrainment term, the vertical advection term, and the term for horizontal advection across the bottom of the mixed layer [Eq. (1)]. The entrainment term consists of temperature gradient $(\Delta T / h)$ and the temporal tendency of mixed layer depth $\left(\partial_{t} h\right)$. An 

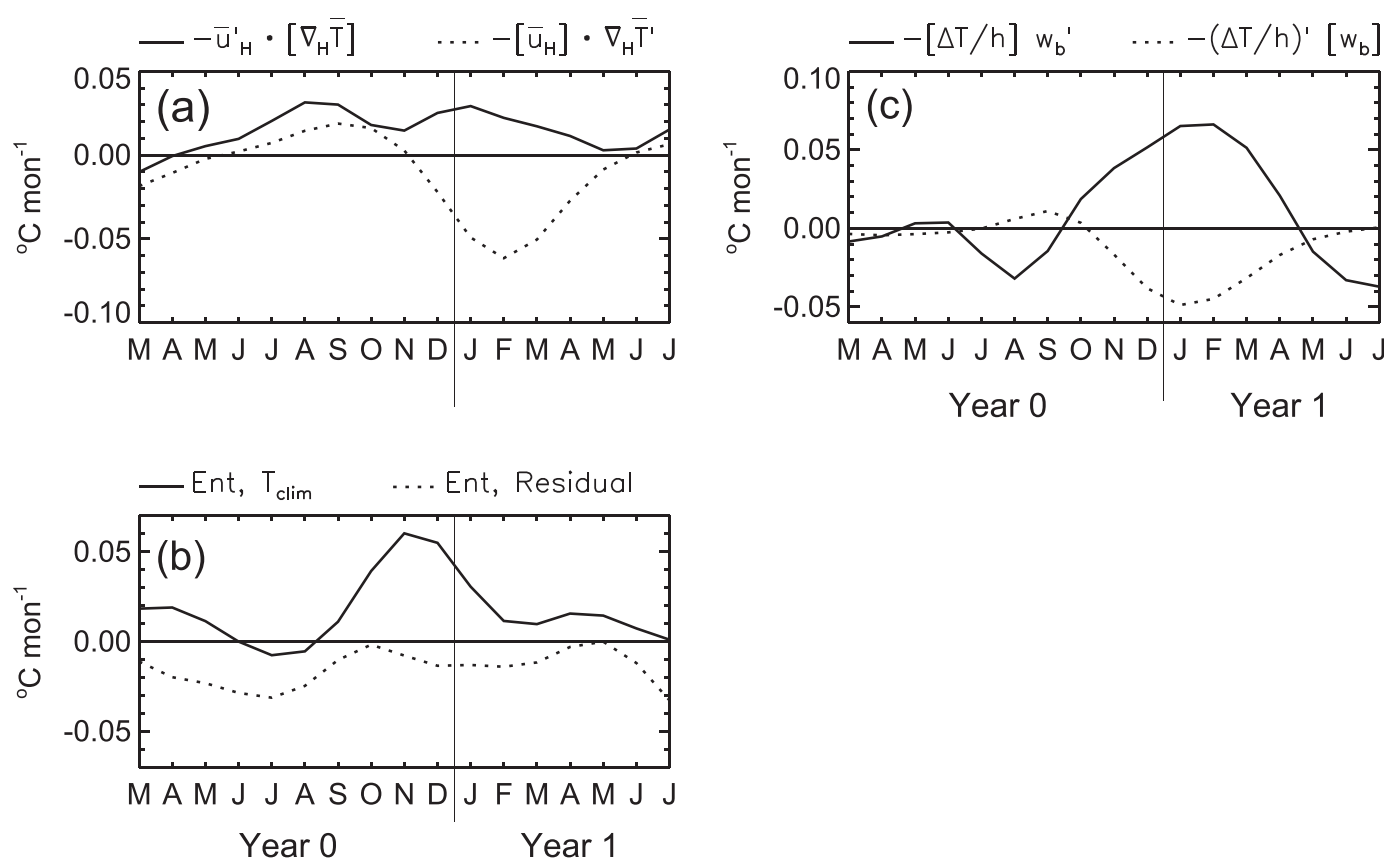

FIG. 10. Anomalies averaged over the off-Bangladesh box $\left(20^{\circ}-23^{\circ} \mathrm{N}, 88^{\circ}-92^{\circ} \mathrm{E}\right)$ regressed onto the normalized DJF mean of OFES SST anomalies averaged over the same box. (a) Contributions to the horizontal advection term from current anomalies $\left(-{\overline{\mathbf{u}_{H}}}^{\prime} \cdot\left[\nabla_{H} \bar{T}\right]\right.$; solid line) and temperature anomalies $\left(-\left[\overline{\mathbf{u}}_{H}\right] \cdot \nabla_{H} \bar{T}^{\prime}\right.$; dotted line). (b) The entrainment term anomalies calculated with climatological temperature (solid line) and the difference between the total entrainment term anomalies and the one calculated from climatological temperature (dotted line). (c) Contributions to the vertical advection term across the bottom of the mixed layer from vertical velocity anomalies $\left(-[\Delta T / h] w_{b}^{\prime}\right.$; solid line $)$ and temperature gradient anomalies $\left(-(\Delta T / h)^{\prime}\left[w_{b}\right]\right.$; dotted line $)$. A 3-month triangle filter was applied twice.

anomaly of the entrainment term arises from anomalies of either $\Delta T / h$ or $\partial_{t} h$. To eliminate the influence of temperature gradient anomalies, we recalculate the entrainment term replacing temperature with its climatology. The results show a warming tendency after September of year 0 (Fig. 10b), when climatological temperature shows an inversion (Fig. 7b). The anomalous deepening of the mixed layer (Fig. 9d) entrains more warm water from subsurface, resulting in anomalous warming of the surface mixed layer. The effect of temperature gradient anomalies, which is calculated as the difference between the total entrainment term anomalies and the one from climatological temperature, is relatively small (Fig. 10b).

An anomaly of the vertical advection term across the bottom of the mixed layer is decomposed as follows:

$$
\left(-\frac{\Delta T}{h} w_{b}\right)^{\prime}=-\left[\frac{\Delta T}{h}\right] w_{b}^{\prime}-\left(\frac{\Delta T}{h}\right)^{\prime}\left[w_{b}\right] .
$$

The contribution from a vertical velocity anomaly, the first term on the rhs of Eq. (5), shows a warming anomaly from October of year 0 to April of year 1 (Fig. 10c). The regressed vertical velocity shows a tendency of upwelling anomalies from November of year 0 to June of year 1 , although the pattern is quite patchy (figure not shown). Wind anomalies regressed onto the box-averaged SST anomalies are southerly from November of year 0 to March of year 1, the amplitude of which is larger in the eastern half of the bay than in the west (Fig. 12a). The resulting Ekman upwelling anomalies bring more warm water from subsurface to the surface and contribute to warming. Ekman pumping anomalies are small in magnitude in the northern Bay of Bengal, but the temperature inversion is clearest in this region (Fig. 12b), which causes the coastally trapped pattern of interannual SST variability shown in Fig. 3. The second term of Eq. (5) shows cooling anomalies from October of year 0 to May of year 1 (Fig. 10c). Both temperature difference anomalies $\left(\Delta T^{\prime}\right)$ and mixed layer depth anomalies $\left(h^{\prime}\right)$ contribute to these cooling anomalies. Anomalies of horizontal advection across the bottom of the mixed layer, $-\left[(\Delta T / h) \mathbf{u}_{\mathrm{Hb}} \cdot \nabla_{H} h\right]^{\prime}$, are small in magnitude and thus neglected.

In summary, the generation mechanisms of SST anomalies off Bangladesh are largely affected by the temperature inversion in fall and winter, which are characterized by cool water trapped in the surface mixed layer and warm water below. We summarize the mechanisms for the 

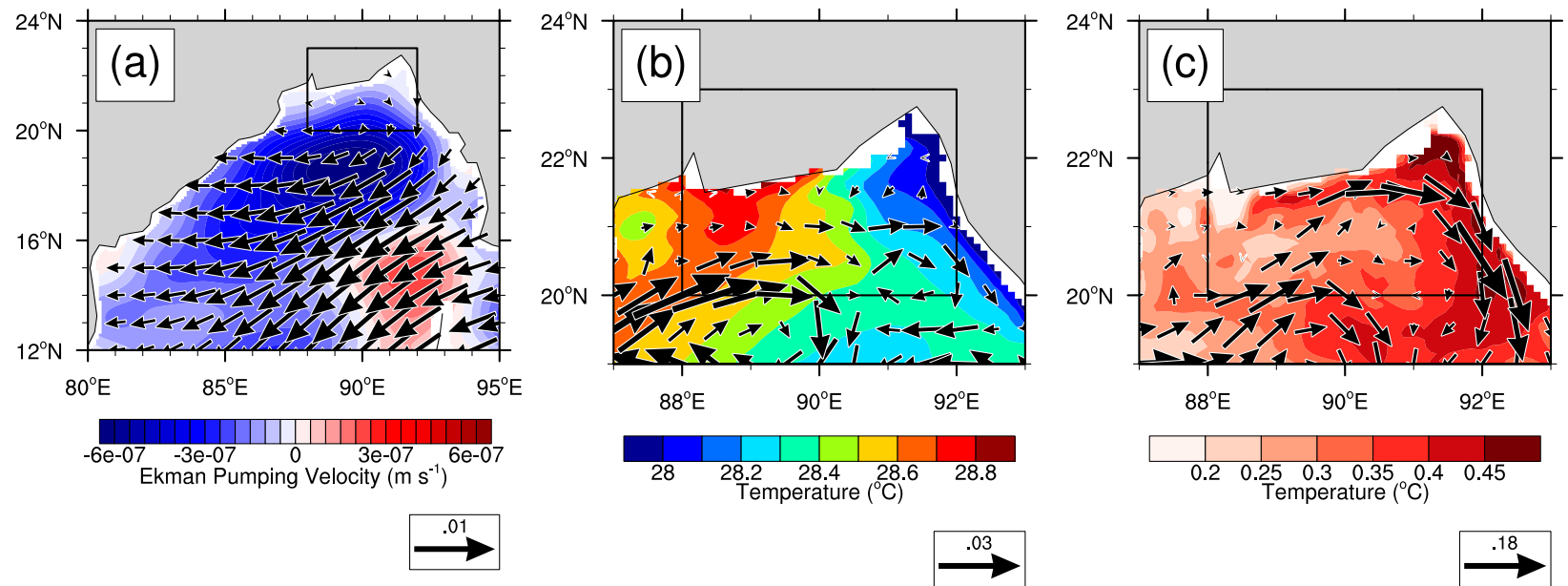

FIG. 11. (a) Regressed Ekman pumping velocity anomalies (colors) and surface wind stress anomalies (vectors) averaged over JuneSeptember of year 0. (b) Regressed horizontal velocity anomalies $\overline{\left(\mathbf{u}_{H}\right.}$ ) averaged over June-September of year 0 (vectors) superposed on climatological mixed layer temperature $([\bar{T}])$ averaged over June-September (colors). (c) Climatological horizontal velocity ([$\left.\left.\overline{\mathbf{u}_{H}}\right]\right)$ averaged over January-March (vectors) superposed on regressed mixed layer temperature anomalies $\left(\bar{T}^{\prime}\right)$ averaged over January-March of year 1 (colors). Surface wind stress and Ekman pumping velocity are obtained from OFES output. Anomalies are regressed onto the normalized DJF mean of OFES SST anomalies averaged over the off-Bangladesh box $\left(20^{\circ}-23^{\circ} \mathrm{N}, 88^{\circ}-92^{\circ} \mathrm{E}\right)$. The results do not change largely if we use a slightly different averaging period.

generation of a positive SST anomaly below. When Ekman upwelling is stronger and/or the surface mixed layer is deepened more than normal in fall and winter in the northern bay, more subsurface warm water is entrained to the surface, resulting in anomalous warming. The thicker-than-normal mixed layer increases the heat capacity of the mixed layer, mitigating climatological cooling and acting as anomalous warming as well.

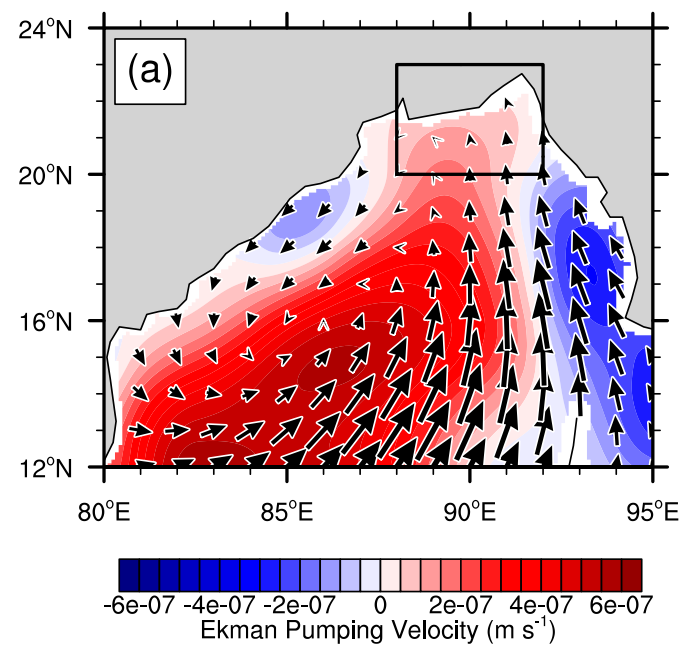

Along with warming due to vertical diffusion at the bottom of the mixed layer, all the processes work to warm the mixed layer and lead to a positive SST anomaly. The surface heat flux anomalies are negative, most of which is accounted for by the enhancement of evaporative cooling caused by the positive SST anomaly, but oceanic warming overcomes the heat loss to the atmosphere. A negative SST anomaly would be generated via similar processes

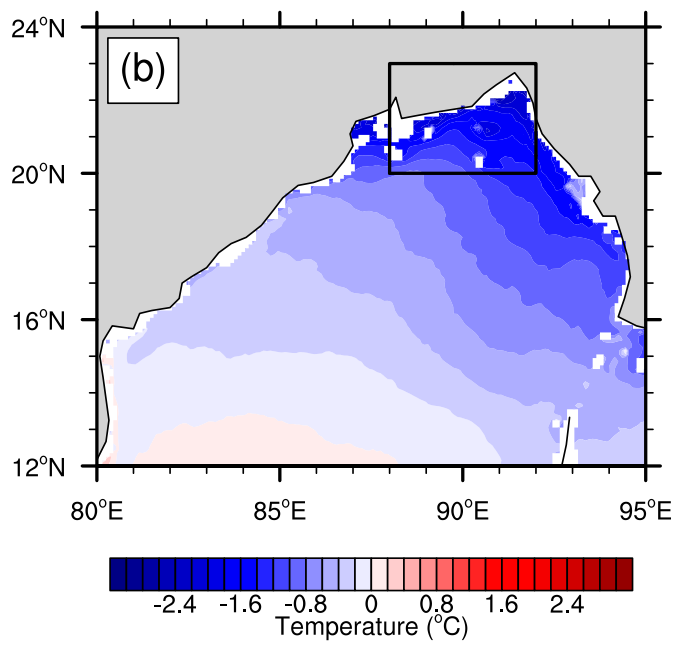

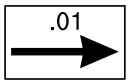

FIG. 12. (a) As in Fig. 11a, but for the average over November of year 0 to March of year 1. (b) Climatological difference between the mixed layer temperature and temperature at the bottom of the mixed layer $\left([\Delta T]=\left[\bar{T}-T_{b}\right]\right)$ averaged over November-March. The results do not change largely if we use a slightly different averaging period. 
but of the opposite polarity. The SST anomalies off Bangladesh are initiated in summer by horizontal heat advection.

\section{Relationship with climate modes}

In this section we seek the relationship between interannual variability in off-Bangladesh SST and climate modes in the Indo-Pacific regions, that is, El NiñoSouthern Oscillation (ENSO) and the Indian Ocean dipole (IOD). SST variability related to these climate modes shifts tropical convection and excites anomalous atmospheric circulations. Ashok et al. (2001) and Terao et al. (2013) demonstrated that ENSO and IOD have significant impacts on precipitation variability in Bangladesh and the northern Bay of Bengal. The associated variability in surface wind may affect SST off Bangladesh via the processes described in the previous section. On the other hand, these climate modes can be predicted using coupled ocean-atmosphere general circulation models (CGCMs) with the lead times of a season or more (e.g., Barnston et al. 1999; Luo et al. 2007). If we find a linkage between off-Bangladesh SST and these climate modes, it may indicate predictability of offBangladesh SST.

As is done conventionally, we use Niño-3.4 SST and the Indian Ocean dipole mode index as measures of ENSO and the IOD, respectively. We base our analysis on NOAA OI SST and OFES SST and omit to use TMI SST here, because of its short time series. Niño-3.4 SST and the IOD index are regressed onto the DJF off-Bangladesh SST, the results of which illustrate climate mode variability when off-Bangladesh SST anomalies are positive. The results show that an El Niño event tends to occur in early year 0 (Fig. 13). In late year 0 , a negative IOD event and a La Niña event occur. The results from NOAA OI SST and OFES output are similar, except that the former emphasizes the relationship with an El Niño event in early year 0 and the latter a La Niña event at the end of year 0 . The tendency that a La Niña event follows El Niño may reflect a biennial tendency of the El Niño-La Niña cycle (Rasmusson et al. 1990).

These statistical relationships can be confirmed by visual inspection of time series (Fig. 14). The clearest example is for 1997/98. El Niño in the end of 1997 turns to La Niña in 1998. A negative IOD event occurs in 1998. SST anomalies off Bangladesh are positive after the El Niño event and concurrently with the negative IOD and La Niña events. A similar relationship can be found in $2009 / 10$. Variability in $1987 / 88$ observed in NOAA OI SST is an example that SST off Bangladesh anomalously rises in relation to the El Niño-La Niña turnabout without clear occurrence of a negative IOD event. (A weak

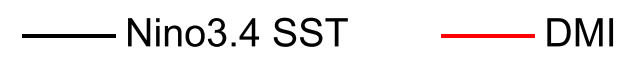

(a)

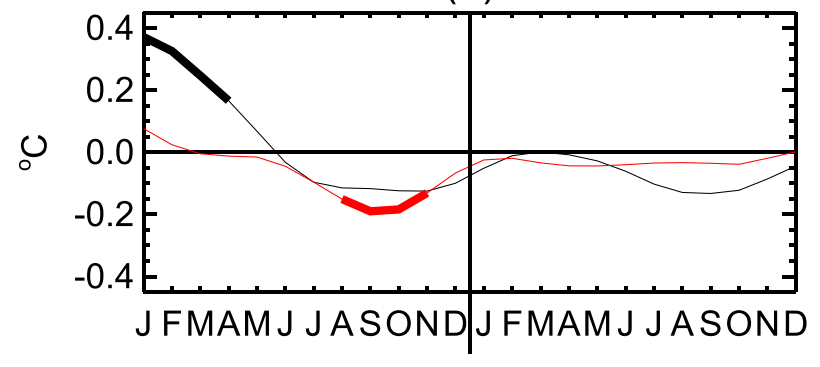

(b)

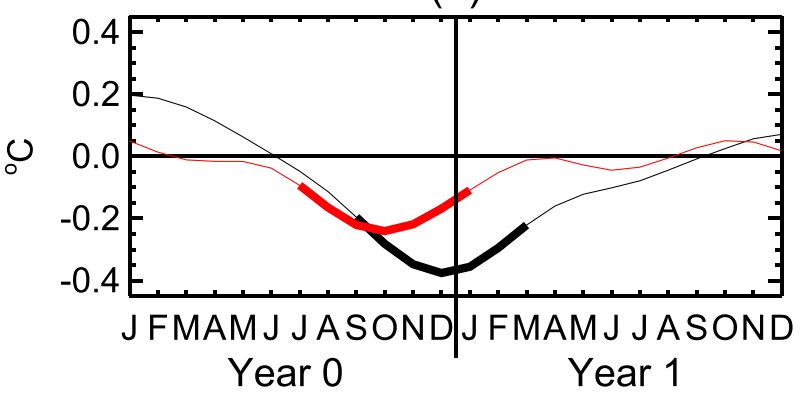

FIG. 13. Niño-3.4 SST anomalies (black) and the IOD mode index anomalies (red) regressed onto the normalized DJF mean of off-Bangladesh SST anomalies averaged over $\left(20^{\circ}-23^{\circ} \mathrm{N}, 88^{\circ}-\right.$ $92^{\circ} \mathrm{E}$ ). Results shown are for (a) NOAA OI SST and (b) SST simulated by OFES. Bold lines show the coefficients that exceed the $90 \%$ confidence limit. A 3-month triangle filter is applied twice before the regression analysis. Niño-3.4 region is $\left(5^{\circ} \mathrm{S}-5^{\circ} \mathrm{N}, 170^{\circ}-\right.$ $\left.120^{\circ} \mathrm{W}\right)$. The IOD mode index is defined as the difference of SST anomalies averaged over $\left(10^{\circ} \mathrm{S}-10^{\circ} \mathrm{N}, 50^{\circ}-70^{\circ} \mathrm{E}\right)$ and $\left(10^{\circ} \mathrm{S}-0^{\circ}, 90^{\circ}-\right.$ $110^{\circ} \mathrm{E}$; Saji et al. 1999).

tendency of negative IOD can be seen in OFES SST in this period.) Variability that does not fit the statistical relation is found in 1983 in NOAA OI SST, when SST off Bangladesh is anomalously low despite the concurrent La Niña and negative IOD events. OFES SST shows a similar combination of negative off-Bangladesh SST anomalies, La Niña, and negative IOD events from 1999 to 2001. Note that the statistical results in Fig. 13 are essentially the same if we remove the biggest warming event of off-Bangladesh SST in 1998/99 from the time series.

The following paragraphs describe the processes behind these statistical relationships. To help the description, we present maps of atmospheric variables regressed onto the off-Bangladesh DJF SST in Fig. 15. Here, off-Bangladesh SST is calculated from OFES SST. This is for the consistency with the results shown in section 4 . The regression onto NOAA OI SST yields similar results, although that onto OFES SST is more robust.

In boreal summer of year 0 , precipitation in the Bay of Bengal and northwestern Pacific Ocean is anomalously 

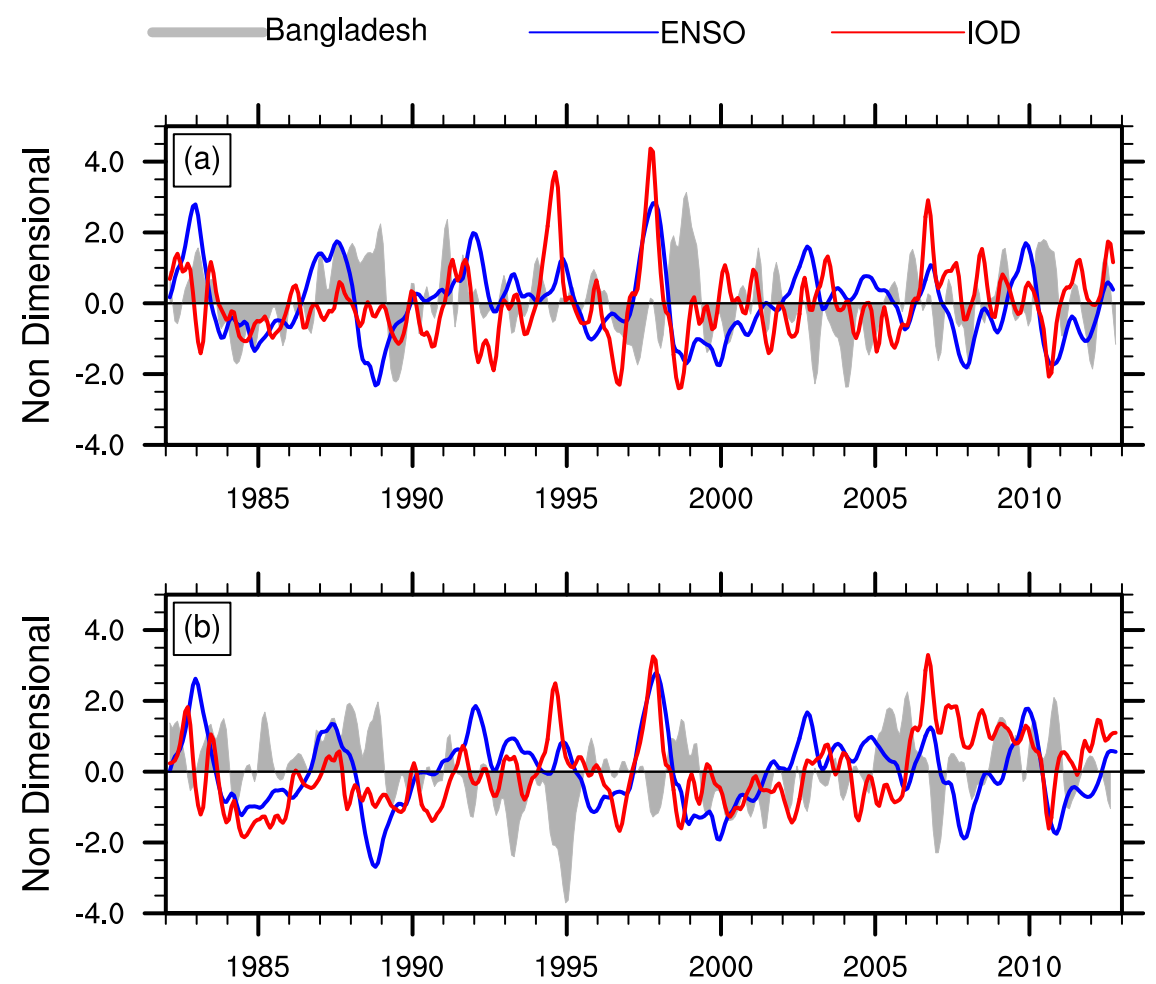

FIG. 14. Interannual anomalies of SST averaged over the off-Bangladesh box (gray), Niño3.4 SST (blue), and the dipole mode index (red) for (a) NOAA OI SST and (b) SST simulated by OFES. The time series are normalized by their standard deviations. A 3-month triangle filter is applied twice. OFES SST is detrended.

low along about $15^{\circ} \mathrm{N}$ (Fig. 15a). Pressure at the lower troposphere is anomalously high along about $20^{\circ} \mathrm{N}$ from the western Pacific to the northern Bay of Bengal (Fig. 15d), which is a pattern typical to the year after an El Niño event. During the mature period of an El Niño event (which is the beginning of year 0 in our time sequence), SST is anomalously warm in the eastern equatorial Pacific (Wallace et al. 1998), owing to which deep atmospheric convection is shifted from the Maritime Continent to the eastern Pacific. The resulting variability in atmospheric circulations leads to changes in surface heat flux and surface wind, which cool SST in the western Pacific and warm SST in the Indian Ocean (Klein et al. 1999; Xie et al. 2002; Lau and Nath 2003). Note that SST off Bangladesh is not related to this SST variability (e.g., Fig. 4b of Huang and Kinter 2002). The high pressure anomalies in the northwestern Pacific Ocean shown in Fig. 15d are generated by the combination of positive and negative SST anomalies in the eastern and western equatorial Pacific, respectively, during the mature phase of El Niño (Wang et al. 2000; Wang and Zhang 2002) and maintained by warm SST anomalies in the Indian Ocean until subsequent summer (Terao and Kubota 2005; Du et al. 2009; Xie et al. 2009). High pressure anomalies extend to the Bay of Bengal (Fig. 15d; Nagura and Konda 2005; Terao et al. 2013), and the resulting northeasterly wind anomalies lead to Ekman downwelling anomalies (Fig. 11a). This initiates the warming of offBangladesh SST, as is described in the previous section.

In the subsequent fall of year 0 , precipitation becomes higher than normal in the eastern equatorial Indian Ocean and lower than normal in the west (Fig. 15b). This is accounted for by the occurrence of a negative IOD event (Fig. 13), which is characterized by positive SST anomalies in the eastern equatorial Indian Ocean and negative in the west (e.g., Saji et al. 1999). In response to the resulting condensational heating, low pressure anomalies are generated off equator in both hemispheres (Fig. 15e). Wind anomalies in the Bay of Bengal are southerly, whose counterclockwise component forces Ekman upwelling anomalies (Fig. 12a), leading to the growth of SST anomalies off Bangladesh. The IOD-related SST anomalies dissipate in boreal winter (Tokinaga and Tanimoto 2004). Variability in winter of year 0 can be attributed to a La Niña event. SSTs in the eastern Pacific are anomalously cold during a La Niña event, and atmospheric deep convection shifts to the west, which leads to heavier-than-normal precipitation over the Maritime 

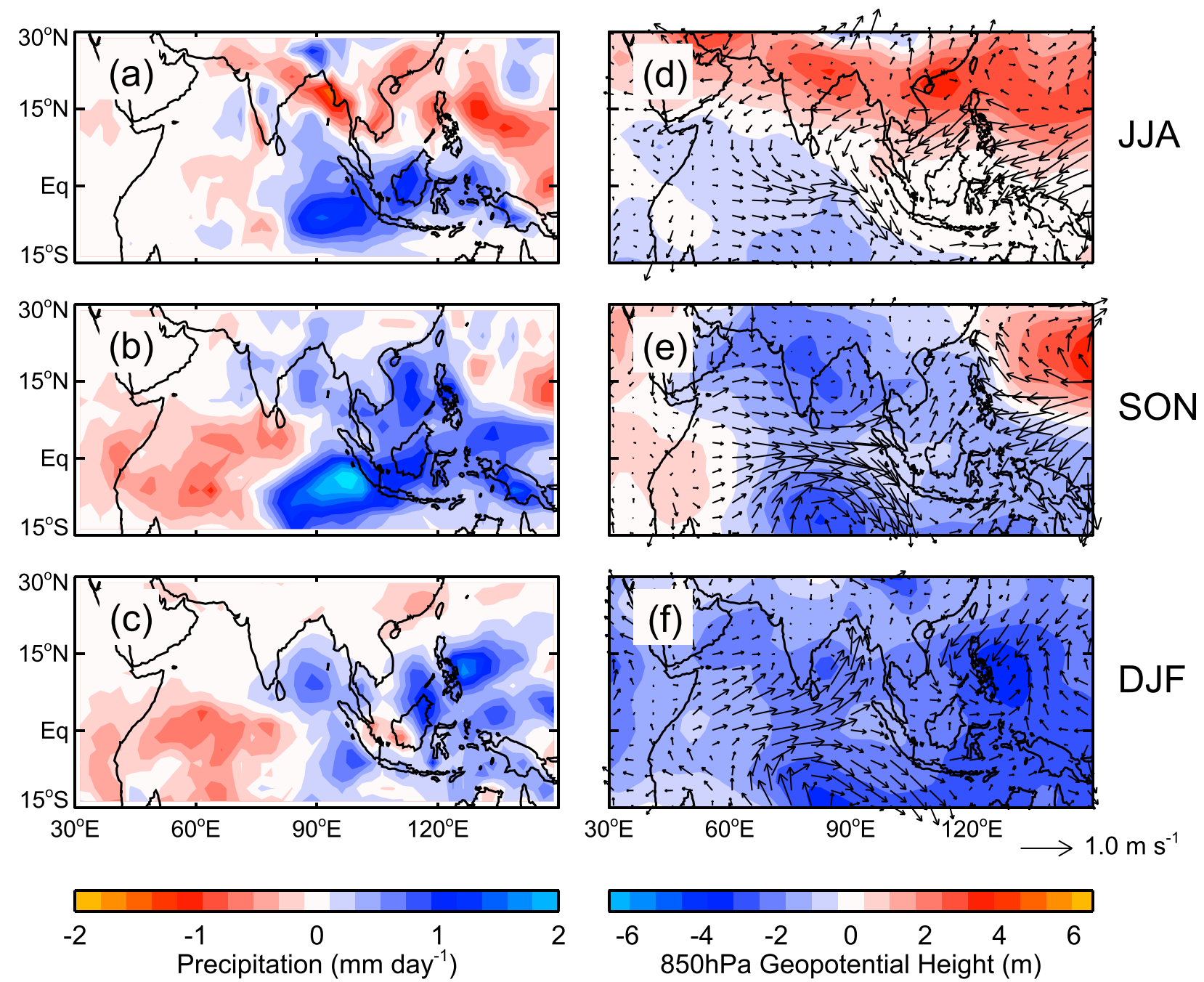

FIG. 15. (a)-(c) GPCP precipitation anomalies and (d)-(f) NCEP 850-hPa geopotential height anomalies (color) and NCEP surface wind anomalies (vectors) regressed onto the normalized DJF mean of OFES SST anomalies averaged over the off-Bangladesh box (20 $23^{\circ} \mathrm{N}, 88^{\circ}-92^{\circ} \mathrm{E}$ ). Shown are the averages for (top) June-August of year 0, (middle) September-November of year 0, and (bottom) December of year 0 and January and February of year 1.

Continent (Fig. 15c; McBride et al. 2003). Heavier precipitation accompanies low pressure anomalies (Fig. 15f), owing to which wind anomalies in the Bay of Bengal are southerly, and the further growth of SST anomalies off Bangladesh is facilitated. If La Niña turns to El Niño and/or a positive IOD event occurs, a negative SST anomaly is generated off Bangladesh by atmospheric anomalies of the opposite sign.

OGCM results show that the upper-ocean thermocline is deepened along the equator in response to westerly wind anomalies in boreal fall and winter of year 0 , which propagates along the periphery of the Bay of Bengal counterclockwise and reaches the offBangladesh region (figure not shown), as is pointed out by Clarke and Liu (1994) and Han and Webster
(2002). However, the ocean bottom in most regions of the off-Bangladesh box is equivalent to or shallower than the typical thermocline depth (about $100 \mathrm{~m}$ ), and wave propagation may be blocked or scattered. Our results indicate that local Ekman pumping and variability in mixed layer depth take a primary role in the generation of SST anomalies off Bangladesh.

\section{Summary}

This study examines SST variability and the mixed layer heat budget off Bangladesh on the seasonal and interannual time scales. The analysis region is strongly affected by the Ganges and Brahmaputra Rivers, which supply freshwater and cause shallow haline stratification, 
resulting in a thin mixed layer, a thick barrier layer, and temperature inversions. The two different satellite SST datasets show a local maximum of SST variability off the coast of Bangladesh (roughly $20^{\circ}-23^{\circ} \mathrm{N}, 88^{\circ}-92^{\circ} \mathrm{E}$ ) on the seasonal and interannual time scales. Climatological SST off Bangladesh peaks in spring and reaches minimum in winter, whereas interannual anomalies tend to grow in summer-fall and peak in winter. The amplitude of SST variability is about $5^{\circ} \mathrm{C}$ on the seasonal time scale and $0.4^{\circ} \mathrm{C}$ on interannual time scales. A high-resolution OGCM reproduces the observed patterns of SST variability both on the seasonal and interannual time scales, although the effect of river runoff is included in a crude manner that is the restoration of model surface salinity toward monthly observations.

The heat budget analysis based on OGCM output shows that the surface mixed layer is cooled by the surface heat flux and warmed by ocean processes on the seasonal time scale. This peculiar heat balance is caused by an inverted vertical profile of temperature. Because of the supply of freshwater by river runoff in summer and fall, sharp haline stratification is formed near the surface. The surface mixed layer is exposed to atmospheric cooling in fall and winter, and SST cools down. However, haline stratification prevents vertical mixing from reaching deep levels, and subsurface water remains warm. The resulting temperature inversion leads to warming due to entrainment, upwelling, and vertical diffusion at the base of the mixed layer.

Temperature inversions also play an essential role in the generation of SST anomalies off Bangladesh on interannual time scales. Described below are the processes that generate a positive SST anomaly. The signs of all anomalies should be reversed for the occurrence of a negative off-Bangladesh SST anomaly. Wind anomalies in the bay are northeasterly in summer, which force Ekman downwelling anomalies and a counterclockwise ocean circulation. Horizontal advection caused by this circulation initiates the warming of the surface mixed layer. In fall and winter, when temperature inversions are clearest, wind anomalies in the bay turn to be southerly. The resulting Ekman pumping anomalies enhance upwelling of subsurface warm water to the surface. Simultaneously, the mixed layer off Bangladesh becomes deeper than normal, which entrains more subsurface warm water to the surface. Also, the thicker than normal mixed layer mitigates climatological atmospheric cooling, and vertical diffusion anomalously warms the surface mixed layer as well. Warming due to these oceanic processes overcome anomalous atmospheric cooling and leads to the growth of positive SST anomalies off Bangladesh.

Further analysis exhibits that SST off Bangladesh tends to be anomalously high after an El Niño event and concurrently with La Niña and negative IOD events. An El Niño event excites a high pressure anomaly in the northwestern Pacific Ocean, which lingers until the subsequent summer and leads to northeasterly wind anomalies in the Bay of Bengal. Negative IOD and La Niña events lead to low pressure anomalies in the bay in fall and winter, which accompany southerly anomalies. These wind anomalies generate positive SST anomalies off Bangladesh via the oceanic processes described above.

The results in this study have revealed that haline stratification and temperature inversions have a substantial role in the generation of SST variability off Bangladesh. The SST variability is trapped near the coast, where the river runoff causes a clear temperature inversion. The dominance of surface heat flux in the mixed layer heat budget found by Howden and Murtugudde (2001) and de Boyer Montégut et al. (2007) was a result of the averaging over a wide area of the Bay of Bengal. Girishkumar et al. (2013) found a significant influence of temperature inversions on the mixed layer heat budget based on observations at the interior of the Bay of Bengal. Observations near the coast possibly exhibit a stronger effect of temperature inversions than they found. The region with the largest SST variability is located just off Bangladesh, which is over or near the shallow continental shelf. The 4.5-layer model Han et al. (2001) used did not include the effect of this bottom topography.

Our results show that the thicker-than-normal mixed layer off Bangladesh leads to anomalous warming. An unaddressed issue of this study is the mechanism of variations of mixed layer thickness. Wind speed off Bangladesh does not show interannual variability related to mixed layer thickness (Figs. 9d,e), and thus, the thick mixed layer is not attributable to the effect of mechanical mixing. Surface heat flux shows cooling anomaly (Fig. 9b), but this is owing to positive SST anomalies and the resulting enhancement of evaporation. It is unlikely that anomalous atmospheric cooling causes unstable stratification via the loss of buoyancy. The region off Bangladesh is strongly affected by river runoff, and the vertical structure in the region may be governed by complicated dynamics, the clarification of which is beyond this study. Our results at least show that SST anomalies off Bangladesh are correlated with mixed layer thickness (Fig. 9d), no matter what causes mixed layer thickness variability.

Another interesting issue is possible asymmetry of positive and negative events. Several studies pointed out asymmetry of anomalies between positive and negative events in relation to ENSO (e.g., Hoerling et al. 1997; Kessler 2002; Larkin and Harrison 2002; An and Jin 2004) and IOD (Ogata et al. 2013). Off-Bangladesh SST is influenced by these climate modes and possibly has 
a similar asymmetry, which we eliminate out by employing a linear regression analysis.

The relationship with the climate modes suggests a possibility that SST variability off Bangladesh is predictable. El Niño-La Niña and IOD can be predicted using a CGCM with the lead times of a season or more (e.g., Barnston et al. 1999; Luo et al. 2007). If interannual SST variability off Bangladesh is successfully predicted, it will be a great benefit to the local community. However, a high vertical resolution will be required to simulate shallow surface haline stratification. The performance of CGCMs should be examined in this regard. Also, accumulation of in situ observations in the coastal area is essential to correctly evaluate the role of temperature inversions on SST variability, in addition to the examination of numerical model output that the current study carried out.

Acknowledgments. The authors thank the OFES team of JAMSTEC for their dedication in developing the model. We also thank $\mathrm{H}$. Annamalai for his helpful comments. We would like to acknowledge the careful and insightful comments from three anonymous reviewers as well. The study is partly supported by the Cooperative Research Grant of NEKKEN, 2013.

\section{APPENDIX A}

\section{Seasonally Stratified Analysis}

Let $\mathrm{SST}_{l}$ be a monthly time series of SST anomalies averaged over the off-Bangladesh box (Fig. 3), where $l(=1,2, \ldots)$ denotes month. If the data source is NOAA OI SST, $l$ ranges from 1 to 373 , where $\mathrm{SST}_{l=1}$ is the value for November 1981, $\mathrm{SST}_{l=2}$ for December 1981, and so on. We can extract a yearly time series from $\mathrm{SST}_{l}$ for a specific month, say August, which we refer to as $\mathrm{SST}_{i}^{\text {Aug }}$. Here $i$ denotes year, and $i=1$ corresponds to August 1982, $i=2$ to August 1983, and so on. The amplitude of SST ${ }^{\text {Aug }}$ can be defined as its standard deviation $\sigma\left(\mathrm{SST}^{\text {Aug }}\right)$. Calculating the standard deviation for each month, we obtain a sequence from January to December $\left[\sigma\left(\mathrm{SST}^{\mathrm{Jan}}\right), \sigma\left(\mathrm{SST}^{\mathrm{Feb}}\right), \ldots, \sigma\left(\mathrm{SST}^{\mathrm{Dec}}\right)\right]$, which shows the seasonality of interannual anomalies, that is, in which season anomalies tend to have large amplitude. Figure $4 \mathrm{~b}$ shows the result, illustrating the tendency for off-Bangladesh SST anomalies to have large amplitude in winter.

The results shown in Figs. 5, 8-13, and 15 are obtained by regressing various variables onto the DJF mean of box-averaged SST. Let $\mathrm{SST}_{i}^{\mathrm{DJF}}$ be the DJF means for NOAA OI SST, where $\mathrm{SST}_{i=1}^{\mathrm{DJF}}$ is the average over December 1982-February 1983, SST $_{i=2}^{\text {DJF }}$ over December
1983-February 1984, and so on. (We have discarded the average over December 1981-February 1982.) Let $Y_{i}^{\text {Aug }}$ be a yearly time series of a variable for August, which consists of values in August 1982, August 1983, and so on. As $Y_{i}^{\text {Aug }}$ is from August 1982 onward, and $\mathrm{SST}_{i}^{\mathrm{DJF}}$ from December 1982 to February 1983 onward, they are seasonally lagged. Regressing $Y_{i}^{\mathrm{Jan}}, Y_{i}^{\mathrm{Feb}}, \ldots$, and $Y_{i}^{\mathrm{Dec}}$ onto $\mathrm{SST}_{i}^{\mathrm{DJF}}$, we obtain a sequence of regression coefficients, which we refer to as the regressions for year 0 . The regressions for year 1 are obtained as follows. Let $Y_{i}^{\text {AugY1 }}$ be a yearly time series of the same variable for August, but now $i=1,2, \ldots$ corresponds to August 1983, August $1984, \ldots$, respectively. As $Y_{i}^{\mathrm{AugY} 1}$ starts from August 1983 and $\operatorname{SST}_{i}^{\mathrm{DJF}}$ from December 1982 to February $1983, \operatorname{SST}_{i}^{\mathrm{DJF}}$ leads $Y_{i}^{\mathrm{AugY} 1}$. The regression of $Y_{i}^{\mathrm{JanY} 1}, Y_{i}^{\mathrm{FebY} 1}, \ldots, Y_{i}^{\mathrm{DecY} 1}$ onto $\mathrm{SST}_{i}^{\mathrm{DJF}}$ gives a sequence, which are results for year 1 . This method is often called the seasonally stratified technique and has been used by previous studies (e.g., Xie et al. 2002, 2009).

For simplicity, let us redefine the independent variable $\mathrm{SST}_{i}^{\mathrm{DJF}}$ as $x$ and the dependent variable as $y$ for the use in the rest of this appendix. Our regression model is $y=b_{1} x+b_{0}+\varepsilon$, where $\varepsilon$ denotes departure from linearity. The ordinary least squares estimates of the regression coefficient $b_{1}$ is $b_{1}=C_{\mathrm{xy}} /\left(\sigma_{x}\right)^{2}$ (Emery and Thomson 2004), where $C_{\mathrm{xy}}=(N-1)^{-1} \sum_{i=1}^{N}\left(x_{i}-\hat{x}\right)\left(y_{i}-\hat{y}\right)$ is the covariance, $\hat{x}=N^{-1} \sum_{i=1}^{N} x_{i}$ is the mean of $x(\hat{y}$ is defined equivalently), $N$ is the number of the sample data, and $\sigma_{x}$ is the standard deviation of $x$. We use anomalies for $x$ and $y$, and thus $\hat{x}=\hat{y}=0$. In addition, we normalize $x$ by its standard deviation before the regression analysis. Thus, $\sigma_{x}=1$, and $b_{1}=C_{\mathrm{xy}}=r \sigma_{y}$, where $r=C_{\mathrm{xy}} /\left(\sigma_{x} \sigma_{y}\right)$ is the correlation coefficient. The resulting $b_{1}$ retains the magnitude of $y$ and has the same units as $y$. This characteristic is useful when magnitude is compared between different datasets (as in Fig. 5) or between the different terms (as in Figs. 8b, 8c, 9a, 10).

As $\hat{x}=\hat{y}=0$ in our case, $b_{0}$ must be zero, if we assume $\hat{\varepsilon}=0$. The regression model can be written as $y=b_{1} x+\varepsilon$. In this case, the regression coefficient $b_{1}$ is the value of $y$ when normalized $x$ is 1 (we have ignored $\varepsilon$ ). The value of $y$ corresponding to $x=-1$ is $-b_{1}$. Thus, the regression coefficient for a negative $x=\mathrm{SST}_{i}^{\mathrm{DJF}}$ is of the opposite sign compared to that for a positive $x$.

\section{APPENDIX B}

\section{Formulation of the Mixed Layer Heat Budget in the Continuous and Discrete Forms}

This appendix derives the equation for the mixed layer heat budget both in continuous and discrete forms 
and discusses calculation errors. The equation of conservation of heat is expressed as

$$
\left(\partial_{t}+\mathbf{u} \cdot \nabla\right) T=\partial_{z}\left(K_{T} \partial_{z} T\right)+D_{h}(T),
$$

where $\mathbf{u}=(u, v, w)$ is a three-dimensional velocity vector and $\boldsymbol{\nabla}=\left(\partial_{x}, \partial_{y}, \partial_{z}\right)$ is the three-dimensional gradient operator. The other symbols are defined in section $4 \mathrm{a}$. Vertically integrating each term from the bottom of the mixed layer $[z=-h(x, y, t)]$ to the sea surface $(z=0)$, we obtain

$$
\begin{aligned}
\int_{-h}^{0} \partial_{t} T d z= & h \partial_{t} \bar{T}+\left(\bar{T}-T_{b}\right) \partial_{t} h, \\
\int_{-h}^{0} \mathbf{u} \cdot \nabla T d z= & h \overline{\mathbf{u}_{H}} \cdot \nabla_{H} \bar{T}+\left(\bar{T}-T_{b}\right)\left(\mathbf{u}_{\mathrm{Hb}} \cdot \nabla_{H} h+w_{b}\right) \\
& +\nabla_{H} \cdot \int_{-h}^{0} \mathbf{u}_{H}^{\prime \prime} T^{\prime \prime} d z,
\end{aligned}
$$

and

$$
\begin{aligned}
\int_{-h}^{0}\left[\partial_{z}\left(K_{T} \partial_{z} T\right)+D_{h}(T)\right] d z= & Q /\left(\rho_{0} c_{p}\right)-\left.\left(K_{T} \partial_{z} T\right)\right|_{b} \\
& +\int_{-h}^{0} D_{h}(T) d z,
\end{aligned}
$$

where the Leibniz integral rule, the assumption of a rigid lid surface $(w=0$ at $z=0)$ and the continuity equation $(\boldsymbol{\nabla} \cdot \mathbf{u}=0)$ are used. Double prime denotes the deviation from the mixed layer average $\left(X^{\prime \prime}=X-\bar{X}\right.$, where $X$ is an arbitrary variable). As $h$ is the mixed layer depth, the term involving double prime variables is small in magnitude and is thus ignored below. The boundary condition at the sea surface,

$$
K_{T} \partial_{z} T=Q /\left(\rho_{0} c_{p}\right) \quad \text { at } \quad z=0,
$$

is used to obtain Eq. (B4).

To express the above terms in a discrete form, we prepare several additional symbols. We use the superscripts $i, j, k$, and $l$ to specify zonal, meridional, vertical, and temporal grid indices, respectively, in this appendix. We omit the grid indices if it does not confuse the discussion. The variables $\Delta x^{i, j}, \Delta y^{i, j}$ and $\Delta t$ are zonal, meridional, and temporal grid intervals, respectively. The variable $\Delta z^{k}$ denotes the vertical thickness of the $k$ th temperature grid, whereas $\Delta Z^{k}$ denotes the vertical distance between the depths where $T^{k}$ and $T^{k+1}$ are defined. The variable $w^{k}$ denotes vertical velocity at the bottom face of a $T^{k}$ cell. The bottom level of the mixed layer is denoted by $k_{b}^{i, j, l}$, and the mixed layer thickness is calculated as $h^{i, j, l}=\sum_{k=1}^{k_{i}^{i, j l} l} \Delta z^{k}$. The following variables are defined on the eastern, western, northern, and southern faces of a temperature cell:

$k_{\mathrm{be}}^{i, j}=\min \left(k_{b}^{i, j}, k_{b}^{i+1, j}\right) ; \quad k_{\mathrm{bw}}^{i, j}=\min \left(k_{b}^{i, j}, k_{b}^{i-1, j}\right) ;$

$k_{\mathrm{bn}}^{i, j}=\min \left(k_{b}^{i, j}, k_{b}^{i, j+1}\right) ; \quad k_{\mathrm{bs}}^{i, j}=\min \left(k_{b}^{i, j}, k_{b}^{i, j-1}\right) ;$

$h_{e}^{i, j}=\sum_{k=1}^{k_{b e}^{i, j}} \Delta z^{k} ; \quad h_{w}^{i, j}=\sum_{k=1}^{k_{b w}^{i, j}} \Delta z^{k} ; \quad h_{n}^{i, j}=\sum_{k=1}^{k_{b n}^{i, j}} \Delta z^{k} ;$

$h_{s}^{i, j}=\sum_{k=1}^{k_{b s}^{i, j}} \Delta z^{k}$

$\bar{u}_{e}^{i, j}=\left(h_{e}^{i, j}\right)^{-1} \sum_{k=1}^{k_{b e}^{i, j}} u_{e}^{i, j, k} \Delta z^{k} ; \quad \bar{u}_{w}^{i, j}=\left(h_{w}^{i, j}\right)^{-1} \sum_{k=1}^{k_{b w}^{i, j}} u_{w}^{i, j, k} \Delta z^{k} ;$

$\bar{v}_{n}^{i, j}=\left(h_{n}^{i, j}\right)^{-1} \sum_{k=1}^{k_{b n}^{i, j}} v_{n}^{i, j, k} \Delta z^{k} ; \quad \bar{v}_{s}^{i, j}=\left(h_{s}^{i, j}\right)^{-1} \sum_{k=1}^{k_{b s}^{i, j}} v_{s}^{i, j, k} \Delta z^{k}$

where $u_{e}^{i, j, k}$ and $u_{w}^{i, j, k}$ are zonal velocity at the eastern and western faces of a temperature cell, respectively, and $v_{n}^{i, j, k}$ and $v_{s}^{i, j, k}$ are meridional velocity at the northern and southern faces of a temperature cell, respectively. A similar definition applies to $T_{e}^{i, j, k}, T_{w}^{i, j, k}, T_{n}^{i, j, k}, T_{s}^{i, j, k}, \bar{T}_{e}^{i, j}$, $\bar{T}_{w}^{i, j}, \bar{T}_{n}^{i, j}$, and $\bar{T}_{s}^{i, j}$. The OGCM we use is on a rectangular Arakawa staggered B grid (Bryan 1969), and the variables defined at the faces of a $T$ cell are calculated by linear interpolation.

The discrete form of Eq. (B2) for the $i$ th and $j$ th $T$ grid is

$$
\begin{aligned}
& \sum_{k=1}^{k_{b}^{l+1}}\left(T^{k, l+1}-T^{k, l}\right) \Delta z^{k}(\Delta t)^{-1} \\
& \quad=h^{l}\left(\bar{T}^{l+1}-\bar{T}^{l}\right)(\Delta t)^{-1}+(\mathrm{ENT}),
\end{aligned}
$$

where we have omitted the superscripts $i$ and $j$. The first term on the rhs is the tendency of mixed layer temperature. The entrainment term (ENT) is formulated as

$$
(\mathrm{ENT})=a(\Delta t)^{-1} \sum_{k=K 1+1}^{K 2}\left(\bar{T}^{l+1}-T^{k, l}\right) \Delta z^{k},
$$

where $a=\operatorname{sgn}\left(k_{b}^{l+1}-k_{b}^{l}\right), \quad \mathrm{K} 1=\min \left(k_{b}^{l}, k_{b}^{l+1}\right), \quad$ and $\mathrm{K} 2=\max \left(k_{b}^{l}, k_{b}^{l+1}\right)$. The function sgn is the sign function. This formulation is essentially the same as that of Kim et al. (2006). The discrete form of Eq. (B3) for the $i$ th and $j$ th grid is 


$$
\begin{aligned}
\sum_{k=1}^{k_{b}} & {\left[u_{e}^{k} T_{e}^{k}-u_{w}^{k} T_{w}^{k}-T^{k}\left(u_{e}^{k}-u_{w}^{k}\right)\right] \Delta z^{k}(\Delta x)^{-1} } \\
+ & \sum_{k=1}^{k_{b}}\left[v_{n}^{k} T_{n}^{k}-v_{s}^{k} T_{s}^{k}-T^{k}\left(v_{n}^{k}-v_{s}^{k}\right)\right] \Delta z^{k}(\Delta y)^{-1}-\left[w^{k_{b}} T^{k_{b}}+\sum_{k=1}^{k_{b}} T^{k}\left(w^{k-1}-w^{k}\right)\right] \\
= & {\left[h_{e} \overline{u_{e}}\left(\overline{T_{e}}-\bar{T}\right)-h_{w} \overline{u_{w}}\left(\overline{T_{w}}-\bar{T}\right)\right](\Delta x)^{-1}+\left[h_{n} \overline{v_{n}}\left(\overline{T_{n}}-\bar{T}\right)-h_{s} \overline{v_{s}}\left(\overline{T_{s}}-\bar{T}\right)\right](\Delta y)^{-1} } \\
& +\left[H\left(k_{b}-k_{\mathrm{be}}\right) \sum_{k=k_{\mathrm{be}}+1}^{k_{b}} u_{e}^{k}\left(T_{e}^{k}-\bar{T}\right) \Delta z^{k}-H\left(k_{b}-k_{\mathrm{bw}}\right) \sum_{k=k_{\mathrm{bw}}+1}^{k_{b}} u_{w}^{k}\left(T_{w}^{k}-\bar{T}\right) \Delta z^{k}\right](\Delta x)^{-1} \\
& +\left[H\left(k_{b}-k_{\mathrm{bn}}\right) \sum_{k=k_{\mathrm{bn}}+1}^{k_{b}} v_{n}^{k}\left(T_{n}^{k}-\bar{T}\right) \Delta z^{k}-H\left(k_{b}-k_{\mathrm{bs}}\right) \sum_{k=k_{\mathrm{bs}}+1}^{k_{b}} v_{s}^{k}\left(T_{s}^{k}-\bar{T}\right) \Delta z^{k}\right](\Delta y)^{-1}+w^{k_{b}}\left(\bar{T}-T^{k_{b}}\right) .
\end{aligned}
$$

Again, we have omitted the superscripts $i$ and $j$, and $H(x)=1$ if $x>0$ and 0 otherwise. The first, second, and third terms on the left-hand side (lhs) of Eq. (B6) are the discrete forms of $\int_{-h}^{0} u \partial_{x} T d z, \int_{-h}^{0} v \partial_{y} T d z$, and $\int_{-h}^{0} w \partial_{z} T d z$, respectively. The first and second terms on the rhs are the discrete forms of $h \bar{u} \partial_{x} \bar{T}$ and $h \bar{v} \partial_{y} \bar{T}$, respectively. The third and fourth terms on the rhs are the discrete versions of $\left(\bar{T}-T_{b}\right) u_{b} \partial_{x} h$ and $\left(\bar{T}-T_{b}\right) v_{b} \partial_{y} h$, respectively. The last term on the rhs corresponds to $\left(\bar{T}-T_{b}\right) w_{b}$. The assumptions of a rigid lid and the continuity equation are used. Equation (B4) is written in a discrete form as

$$
\begin{aligned}
& \sum_{k=1}^{k_{b}}\left[K_{T}^{k-1}\left(T^{k-1}-T^{k}\right)\left(\Delta Z^{k-1}\right)^{-1}-K_{T}^{k}\left(T^{k}-T^{k+1}\right)\left(\Delta Z^{k}\right)^{-1}+D_{h}\left(T^{k}\right) \Delta z^{k}\right] \\
& \quad=Q /\left(\rho_{0} c_{p}\right)-K_{T}^{k_{b}}\left(T^{k_{b}}-T^{k_{b}+1}\right)\left(\Delta Z^{k_{b}}\right)^{-1}+\sum_{k=1}^{k_{b}} D_{h}\left(T^{k}\right) \Delta z^{k} .
\end{aligned}
$$

The terms on the lhs of Eqs. (B5)-(B7) are the ones used in the model integration. As the model's heat budget is closed, we can calculate a closed mixed layer heat budget using Eqs. (B5)-(B7), if we have output at every model time step. The output actually available is snapshots taken every 3 days, the use of which causes sampling errors. Thus, we cannot remove all the errors in the calculation, but we can check calculation errors by comparing the left- and right-hand sides of Eqs. (B5)(B7) using model output. Results show that the discrepancy is a few percent at most, indicating that calculation errors are negligible.

\section{REFERENCES}

Akhil, V. P., and Coauthors, 2014: A modeling study of the processes of surface salinity seasonal cycle in the Bay of Bengal. J. Geophys. Res. Oceans, 119, 3926-3947, doi:10.1002/ 2013JC009632.

An, S.-I., and F.-F. Jin, 2004: Nonlinearity and asymmetry of ENSO. J. Climate, 17, 2399-2412, doi:10.1175/1520-0442(2004)017<2399: NAAOE $>2.0 . C O ; 2$.

Ashok, K., Z. Guan, and T. Yamagata, 2001: Impact of the Indian Ocean dipole on the relationship between the Indian Monsoon rainfall and ENSO. Geophys. Res. Lett., 28, 4499-4502, doi:10.1029/2001GL013294.
Barnston, A. G., M. H. Glantz, and Y. He, 1999: Predictive skill of statistical and dynamical climate models in SST forecasts during the 1997/98 El Niño episode and the 1998 La Niña onset. Bull. Amer. Meteor. Soc., 80, 217-243, doi:10.1175/1520-0477(1999)080<0217:PSOSAD>2.0.CO;2.

Boyer, T. P., S. Levitus, J. I. Antonov, M. E. Conkright, T. O'Brien, and C. Stephens, 1998a: Salinity of the Atlantic Ocean. Vol. 4, World Ocean Atlas 1998, NOAA Atlas NESDIS 30 , $166 \mathrm{pp}$.

,,,,,----- and,$- 1998 \mathrm{~b}$ : Salinity of the Pacific Ocean. Vol. 5, World Ocean Atlas 1998, NOAA Atlas NESDIS 31, 166 pp.

$-,-,-,-,-\longrightarrow,-$, and B. Trotsenko, 1998c: Salinity of the Indian Ocean. Vol. 6, World Ocean Atlas 1998, NOAA Atlas NESDIS 32, 166 pp.

Bryan, K., 1969: A numerical method for the study of the circulation of the world ocean. J. Comput. Phys., 4, 347-376, doi:10.1016/ 0021-9991(69)90004-7.

Castro, S. L., G. A. Wick, P. J. Minnett, A. T. Jessup, and W. J. Emery, 2010: The impact of measurement uncertainty and spatial variability on the accuracy of skin and subsurface regression-based sea surface temperature algorithms. Remote Sens. Environ., 114, 2666-2678, doi:10.1016/j.rse.2010.06.003.

Clarke, A. J., and X. Liu, 1994: Interannual sea level in the northern and eastern Indian Ocean. J. Phys. Oceanogr., 24, 1224-1235, doi:10.1175/1520-0485(1994)024<1224:ISLITN>2.0.CO;2.

Constatin de Magney, G. C., and Coauthors, 2008: Environmental signatures associated with cholera epidemics. 
Proc. Natl. Acad. Sci. USA, 105, 17 676-17 681, doi:10.1073/ pnas.0809654105.

Davis, R., 1976: Predictability of sea surface temperature and sea level pressure anomalies over the North Pacific Ocean. J. Phys. Oceanogr., 6, 249-266, doi:10.1175/1520-0485(1976)006<0249: POSSTA $>2.0 . \mathrm{CO} ; 2$.

de Boyer Montégut, C., J. Vialard, S. S. C. Shenoi, D. Shankar, F. Durand, C. Ethé, and G. Madec, 2007: Simulated seasonal and interannual variability of the mixed layer heat budget in the northern Indian Ocean. J. Climate, 20, 3249-3268, doi:10.1175/ JCLI4148.1.

Du, Y., S.-P. Xie, G. Huang, and K. Hu, 2009: Role of air-sea interaction in the long persistence of El Niño-induced north Indian Ocean warming. J. Climate, 22, 2023-2038, doi:10.1175/ 2008JCLI2590.1.

Emery, W. J., and R. E. Thomson, 2004: Data Analysis Methods in Physical Oceanography. 2nd ed. Elsevier, 654 pp.

—, D. J. Baldwin, P. Schlüssel, and R. W. Reynolds, 2001: Accuracy of in situ sea surface temperatures used to calibrate infrared satellite measurements. J. Geophys. Res., 106, 23872405, doi:10.1029/2000JC000246.

Fomby, T. B., and T. J. Vogelsang, 2002: The application of sizerobust trend statistics to global-warming temperature series. J. Climate, 15, 117-123, doi:10.1175/1520-0442(2002)015<0117: TAOSRT $>2.0 . \mathrm{CO} ; 2$.

Gadgil, S., P. V. Joseph, and N. V. Joshi, 1984: Ocean-atmosphere coupling over monsoon regions. Nature, 312,141-143, doi:10.1038/ $312141 \mathrm{a} 0$.

Gentemann, C. L., F. J. Wentz, C. A. Mears, and D. K. Smith, 2004: In situ validation of Tropical Rainfall Measuring Mission microwave sea surface temperatures. J. Geophys. Res., 109, C04021, doi:10.1029/2003JC002092.

Girishkumar, M. S., M. Ravichandran, and M. J. McPhaden, 2013: Temperature inversions and their influence on the mixed layer heat budget during the winters of 2006-2007 and 2007-2008 in the Bay of Bengal. J. Geophys. Res. Oceans, 118, 2426-2437, doi:10.1002/jgrc.20192.

Han, W., and J. P. McCreary, 2001: Modeling salinity distributions in the Indian Ocean. J. Geophys. Res., 106, 859-877, doi:10.1029/ 2000JC000316.

_ , and P. J. Webster, 2002: Forcing mechanisms of sea level interannual variability in the Bay of Bengal. J. Phys. Oceanogr., 32, 216-239, doi:10.1175/1520-0485(2002)032<0216: FMOSLI $>2.0 . \mathrm{CO} ; 2$

_ J. P. McCreary, and K. E. Kohler, 2001: Influence of precipitation minus evaporation and Bay of Bengal rivers on dynamics, thermodynamics, and mixed layer physics in the upper Indian Ocean. J. Geophys. Res., 106, 6895-6916, doi:10.1029/ 2000JC000403.

Hashizume, M., A. S. G. Faruque, T. Terao, M. Yunus, K. Streatfield, T. Yamamoto, and K. Moji, 2011: The Indian Ocean dipole and cholera incidence in Bangladesh: A time-series analysis. Environ. Health Perspect., 119, 239-244, doi:10.1289/ehp.1002302.

Hoerling, M. P., A. Kumar, and M. Zhong, 1997: El Niño, La Niña and the nonlinearity of their teleconnections. J. Climate, 10, 1769-1786, doi:10.1175/1520-0442(1997)010<1769: ENOLNA $>2.0 . \mathrm{CO} ; 2$.

Howden, S. D., and R. Murtugudde, 2001: Effects of river inputs into the Bay of Bengal. J. Geophys. Res., 106, 19825-19843, doi:10.1029/2000JC000656.

Huang, B., and J. L. Kinter III, 2002: Interannual variability in the tropical Indian Ocean. J. Geophys. Res., 107, 3199, doi:10.1029/ 2001JC001278.
Huffman, G. J., and Coauthors, 1997: The Global Precipitation Climatology Project (GPCP) combined precipitation data set. Bull. Amer. Meteor. Soc., 78, 5-20, doi:10.1175/ 1520-0477(1997)078<0005:TGPCPG > 2.0.CO;2.

Janowiak, J. E., A. Gruber, C. R. Kondragunta, R. E. Livezey, and G. J. Huffman, 1998: A comparison of the NCEP-NCAR reanalysis prediction and the GPCP rain gauge-satellite combined dataset with observational error considerations. J. Climate, 11, 2960-2979, doi:10.1175/1520-0442(1998)011<2960: ACOTNN $>2.0 . \mathrm{CO} ; 2$

Kalnay, E., and Coauthors, 1996: The NCEP/NCAR 40-Year Reanalysis Project. Bull. Amer. Meteor. Soc., 77, 437-471, doi:10.1175/1520-0477(1996)077<0437:TNYRP>2.0.CO;2.

Kessler, W. S., 2002: Is ENSO a cycle or a series of events? Geophys. Res. Lett., 29, 2125, doi:10.1029/2002GL015924.

Kim, S.-B., I. Fukumori, and T. Lee, 2006: The closure of the ocean mixed layer temperature budget using level-coordinate model fields. J. Atmos. Oceanic Technol., 23, 840-853, doi:10.1175/ JTECH1883.1.

Klein, S. A., B. J. Soden, and N.-C. Lau, 1999: Remote sea surface temperature variations during ENSO: Evidence for a tropical atmospheric bridge. J. Climate, 12, 917-932, doi:10.1175/ 1520-0442(1999)012<0917:RSSTVD > 2.0.CO;2.

Large, W. G., J. C. McWilliams, and S. C. Doney, 1994: Oceanic vertical mixing - A review and a model with a nonlocal boundary layer parameterization. Rev. Geophys., 32, 363-403, doi:10.1029/94RG01872.

Larkin, N. K., and D. E. Harrison, 2002: ENSO warm (El Niño) and cold (La Niña) event life cycles: Ocean surface anomaly patterns, their symmetries, asymmetries, and implications. J. Climate, 15, 1118-1140, doi:10.1175/1520-0442(2002)015<1118: EWENOA $>2.0 . \mathrm{CO} ; 2$.

Lau, N.-C., and M. J. Nath, 2003: Atmosphere-ocean variations in the Indo-Pacific sector during ENSO episodes. $J$. Climate, 16, 3-20, doi:10.1175/1520-0442(2003)016<0003: AOVITI $>2.0 . \mathrm{CO} ; 2$.

Lobitz, B., L. Beck, A. Huq, B. Wood, G. Fuchs, A. S. G. Faruque, and R. Colwell, 2000: Climate and infectious disease: Use of remote sensing for detection of Vibrio cholerae by indirect measurement. Proc. Natl. Acad. Sci. USA, 97, 1438-1443, doi:10.1073/ pnas.97.4.1438.

Luo, J.-J., S. Masson, S. Behera, and T. Yamagata, 2007: Experimental forecasts of the Indian Ocean dipole using a coupled OAGCM. J. Climate, 20, 2178-2190, doi:10.1175/ JCLI4132.1.

Masumoto, Y., and Coauthors, 2004: A fifty-year eddy-resolving simulation of the world ocean-Preliminary outcomes of OFES (OGCM for the Earth Simulator). J. Earth Simul., 1, $35-56$.

McBride, J. L., M. R. Haylock, and N. Nicholls, 2003: Relationships between the Maritime Continent heat source and the El Niño-Southern Oscillation phenomenon. J. Climate, 16, 2905-2914, doi:10.1175/1520-0442(2003)016<2905: $\mathrm{RBTMCH}>2.0 . \mathrm{CO} ; 2$.

McCreary, J. P., P. K. Kundu, and R. L. Molinari, 1993: A numerical investigation of dynamics, thermodynamics and mixed-layer processes in the Indian Ocean. Prog. Oceanogr., 31, 181-244, doi:10.1016/0079-6611(93)90002-U.

Nagura, M., and M. Konda, 2005: The relationship between the interannual variation of the north Indian Ocean SST induced by surface wind and ENSO during boreal summer. J. Climate, 18, 1942-1956, doi:10.1175/JCLI3378.1. 
, and M. J. McPhaden, 2014: Zonal momentum budget along the equator in the Indian Ocean from a high resolution ocean general circulation model. J. Geophys. Res. Oceans, 119, 4444 4461, doi:10.1002/2014JC009895.

__, Y. Masumoto, and T. Horii, 2014: Meridional heat advection due to mixed Rossby gravity waves in the equatorial Indian Ocean. J. Phys. Oceanogr., 44, 343-358, doi:10.1175/ JPO-D-13-0141.1.

Ogata, T., S.-P. Xie, J. Lan, and X. Zheng, 2013: Importance of ocean dynamics for the skewness of the Indian Ocean dipole mode. J. Climate, 26, 2145-2159, doi:10.1175/ JCLI-D-11-00615.1.

Pacanowski, R. C., and A. Gnanadesikan, 1998: Transit response in a $z$-level ocean model that resolves topography with partial cells. Mon. Wea. Rev., 126, 3248-3270, doi:10.1175/ 1520-0493(1998)126<3248:TRIAZL > 2.0.CO;2.

— Group Tech. Rep. 4, 680 pp.

Rao, R. R., and R. Sivakumar, 2003: Seasonal variability of sea surface salinity and salt budget of the mixed layer of the north Indian Ocean. J. Geophys. Res., 108, 3009, doi:10.1029/ 2001JC000907.

— R. L. Molinari, and J. F. Festa, 1989: Evolution of the climatological near-surface thermal structure of the tropical Indian Ocean: 1. Description of mean monthly mixed layer depth, and sea surface temperature, surface current, and surface meteorological fields. J. Geophys. Res., 94, 10 801-10 815, doi:10.1029/JC094iC08p10801.

Rao, S. A., V. V. Gorpalakrishna, S. R. Shetye, and T. Yamagata, 2002: Why were cool SST anomalies absent in the Bay of Bengal during the 1997 Indian Ocean dipole event? Geophys. Res. Lett., 29, 1559, doi:10.1029/2001GL014645.

Rasmusson, E. M., X. Wang, and C. F. Ropelewski, 1990: The biennial component of ENSO variability. J. Mar. Syst., 1, 71-96, doi:10.1016/0924-7963(90)90153-2.

Reynolds, R. W., and T. M. Smith, 1994: Improved global sea surface temperature analyses using optimum interpolation. J. Climate, 7, 929-948, doi:10.1175/1520-0442(1994)007<0929: IGSSTA $>2.0 . \mathrm{CO} ; 2$.

— N. A. Rayner, T. M. Smith, D. C. Stokes, and W. Wang, 2002: An improved in situ and satellite SST analysis for climate. J. Climate, 15, 1609-1625, doi:10.1175/1520-0442(2002)015<1609: AIISAS $>2.0 . \mathrm{CO} ; 2$.

Roemmich, D., and J. Gilson, 2009: The 2004-2008 mean and annual cycle of temperature, salinity, and steric height in the global ocean from the Argo Program. Prog. Oceanogr., 82, 81100, doi:10.1016/j.pocean.2009.03.004.

Rosati, A., and K. Miyakoda, 1988: A general circulation model for upper ocean circulation. J. Phys. Oceanogr., 18, 1601-1626, doi:10.1175/1520-0485(1988)018<1601:AGCMFU>2.0.CO;2.

Saji, N. H., B. N. Goswami, P. N. Vinayachandran, and T. Yamagata, 1999: A dipole mode in the tropical Indian Ocean. Nature, 401, 360-363.

Sasaki, H., Y. Sasai, M. Nonaka, Y. Masumoto, and S. Kawahara, 2006: An eddy-resolving simulation of the quasi-global ocean driven by satellite-observed wind field. J. Earth Simul., 6, 35-49.

, M. Nonaka, Y. Masumoto, Y. Sasai, H. Uehara, and H. Sakuma, 2008: An eddy-resolving hindcast simulation of the quasiglobal ocean from 1950 to 2003 on the Earth Simulator. High Resolution Numerical Modelling of the Atmosphere and Ocean, K. Hamilton and W. Ohfuchi, Eds., Springer, 157-185.
Sengupta, D., P. K. Ray, and G. S. Bhat, 2002: Spring warming of the eastern Arabian Sea and Bay of Bengal from buoy data. Geophys. Res. Lett., 29, 1734, doi:10.1029/ 2002 GL015340.

Shenoi, S. S. C., D. Shankar, and S. R. Shetye, 2002: Differences in heat budgets of the near-surface Arabian Sea and Bay of Bengal: Implications for the summer monsoon. J. Geophys. Res., 107, 3052, doi:10.1029/2000JC000679.

,$- \ldots$, and -2005 : On the accuracy of the simple ocean data assimilation analysis for estimating heat budgets of the near-surface Arabian Sea and Bay of Bengal. J. Phys. Oceanogr., 35, 395-400, doi:10.1175/JPO-2678.1.

Shetye, S. R., A. D. Gouveia, D. Shankar, S. S. C. Shenoi, P. N. Vinayachandran, D. Sundar, G. S. Michael, and G. Nampoothiri, 1996: Hydrography and circulation in the western Bay of Bengal during the northeast monsoon. J. Geophys. Res., 101, 14 011-14 025, doi:10.1029/95JC03307.

Sprintall, J., and M. Tomczak, 1992: Evidence of the barrier layer in the surface layer of the tropics. J. Geophys. Res., 97, 73057316, doi:10.1029/92JC00407.

Terao, T., and T. Kubota, 2005: East-west SST contrast over the tropical oceans and the post El Niño western North Pacific summer monsoon. Geophys. Res. Lett., 32, L15706, doi:10.1029/ 2005 GL023010.

—, F. Murata, A. Habib, M. S. H. Bhuiyan, S. A. Choudhury, and T. Hayashi, 2013: Impacts of rapid warm-to-cold ENSO transitions on summer monsoon rainfall over the northeastern Indian subcontinent. J. Meteor. Soc. Japan, 91, 1-21, doi:10.2151/ jmsj.2013-101.

Thadathil, P., V. V. Gopalakrishna, P. M. Muraleedharan, G. V. Reddy, N. Araligidad, and S. Shenoy, 2002: Surface layer temperature inversion in the Bay of Bengal. Deep-Sea Res. I, 49, 1801-1818, doi:10.1016/S0967-0637(02)00044-4.

—, P. M. Muraleedharan, R. R. Rao, Y. K. Somayajulu, G. V. Reddy, and C. Revichandran, 2007: Observed seasonal variability of barrier layer in the Bay of Bengal. J. Geophys. Res., 112, C02009, doi:10.1029/2006JC003651.

Tokinaga, H., and Y. Tanimoto, 2004: Seasonal transition of SST anomalies in the tropical Indian Ocean during El Niño and Indian Ocean dipole years. J. Meteor. Soc. Japan, 82, 10071018, doi:10.2151/jmsj.2004.1007.

Vinayachandran, P. N., V. S. N. Murty, and V. Ramesh Babu, 2002: Observations of barrier layer formation in the Bay of Bengal during summer monsoon. J. Geophys. Res., 107, 8018, doi:10.1029/ 2001JC000831.

Wallace, J. M., E. M. Rasmusson, T. P. Mitchell, V. E. Kousky, E. S. Sarachik, and H. von Storch, 1998: On the structure and evolution of ENSO-related climate variability in the tropical Pacific: Lessons from TOGA. J. Geophys. Res., 103, 1424114 259, doi:10.1029/97JC02905.

Wang, B., and Q. Zhang, 2002: Pacific-East Asian teleconnection. Part II: How the Philippine Sea anomalous anticyclone is established during El Niño development. J. Climate, 15, 3252-3265, doi:10.1175/1520-0442(2002)015<3252: PEATPI $>2.0 . \mathrm{CO} ; 2$.

—, R. Wu, and X. Fu, 2000: Pacific-East Asian teleconnection: How does ENSO affect east Asian climate? J. Climate, 13, 1517-1536, doi:10.1175/1520-0442(2000)013<1517: PEATHD $>2.0 . \mathrm{CO} ; 2$.

Wang, J.-W., W. Han, and R. L. Sriver, 2012: Impact of tropical cyclones on the ocean heat budget in the Bay of Bengal during 1999: 2. Processes and interpretations. J. Geophys. Res., 117, C09021, doi:10.1029/2012JC008372. 
Wang, W., and M. J. McPhaden, 2001: What is the mean seasonal cycle of surface heat flux in the equatorial Pacific? J. Geophys. Res., 106, 837-857, doi:10.1029/ 1999JC000076.

Xie, S.-P., H. Annamalai, F. A. Schott, and J. P. McCreary, 2002: Structure and mechanisms of south Indian Ocean climate variability. J. Climate, 15, 864-878, doi:10.1175/ 1520-0442(2002)015<0864:SAMOSI >2.0.CO;2.
_ , K. Hu, J. Hafner, H. Tokinaga, Y. Du, G. Huang, and T. Sampe, 2009: Indian Ocean capacitor effect on Indo-western Pacific climate during the summer following El Niño. J. Climate, 22, 730-747, doi:10.1175/2008JCLI2544.1.

Zaron, E. D., and J. N. Moum, 2009: A new look at Richardson number mixing schemes for equatorial ocean modeling. J. Phys. Oceanogr., 39, 2652-2664, doi:10.1175/ 2009JPO4133.1. 